SUPPLEMENTARY INFORMATION FOR:

\title{
Genetic and biochemical reconstitution of bromoform biosynthesis in Asparagopsis lends insights into seaweed ROS enzymology
}

Hem R. Thapa, ${ }^{1}$ Zhenjian Lin, ${ }^{2}$ Dongqi Yi, ${ }^{1}$ Jennifer E. Smith, ${ }^{3}$ Eric W. Schmidt, ${ }^{2}$ Vinayak Agarwal ${ }^{1,4, *}$

${ }^{1}$ School of Chemistry and Biochemistry, Georgia Institute of Technology

${ }^{2}$ Department of Medicinal Chemistry, University of Utah

${ }^{3}$ Center for Marine Biodiversity and Conservation, Scripps Institution of Oceanography, University of California, San Diego

${ }^{4}$ School of Biological Sciences, Georgia Institute of Technology

*Correspondence: vagarwal@gatech.edu; Ph: 404-385-3798 


\section{MAterials ANd Methods}

\section{Sample collection}

Samples of the filamentous, sporophyte phase of the red macroalga Asparagopsis taxiformis were collected from five different locations: Guam, California, Hawaii, Florida Keys, and Fiji. Samples of Macrocystis pyrifera were collected from the southern California coast (San Diego). Algal biomass for nucleic acid preparation was stored in RNAlater solution (3.54 M ammonium sulfate, $16.7 \mathrm{mM}$ sodium citrate, 13.3 $\mathrm{mM}$ ethylenediaminetetraacetic acid (EDTA), $\mathrm{pH}$ 8.0). Biomass for chemical analysis was stored without any treatment. Both types of biomass samples were kept in a cooler during field collection and samples once brought to the lab were stored at $-80^{\circ} \mathrm{C}$ until further use.

\section{Culturing of Asparagopsis taxiformis}

Upon collection of the filamentous phase of A. taxiformis in California, samples were cultured in the lab at Scripps Institution of Oceanography to allow for further experimentation. Specifically, samples were sorted and cleaned under stereomicroscope to isolate $A$. taxiformis from any other taxa growing within the algal matrix. Roughly $1 \mathrm{~g}$ of wet weight was placed in each of several 2-liter Erlenmeyer flasks filled with autoclaved and UV sterilized seawater from the Scripps Institution of Oceanography's running seawater system. Flasks were sealed with stoppers and all samples were gently aerated with ambient air to allow for a gentle tumble. Seawater was replaced weekly and sample biomass to volume ratios were kept below $5 \mathrm{~g} / \mathrm{L}$. All flasks were cultured on a $12 \mathrm{hr}$ day/light cycle at $50 \mathrm{mE} / \mathrm{cm}^{2} / \mathrm{s}$ at ambient temperature (roughly $22{ }^{\circ} \mathrm{C}$ ).

\section{GC-MS analysis of chemical extracts}

Algal biomass collected either from the field or laboratory were lyophilized for $16 \mathrm{~h}$. Freeze-dried biomass was used for extraction with $\mathrm{MeOH}$. Biomass was soaked in $\mathrm{MeOH}$ for several hours before extraction with vigorous agitation on vortex mixer, centrifuged at $16,000 \times \mathrm{g}$ for $30 \mathrm{~min}$ to remove debris, and an aliquot of supernatant was analyzed by GC-MS (1260G with 7890a MS; Agilent Technologies) in electron ionization (70 eV) mode using a DF-5ms ultra inert GC column (30 m length, $0.25 \mathrm{~mm}$ width and $0.5 \mu \mathrm{M}$ film thickness). Bromoform production quantitation for A. taxiformis and M. pyrifera was quantified based on calibration curves generated from a bromoform standard. The column temperature conditions were as follows: $40^{\circ} \mathrm{C}$ for $3 \mathrm{~min}$, increased to $200^{\circ} \mathrm{C}$ at $10^{\circ} \mathrm{C} / \mathrm{min}$ and held for $1 \mathrm{~min}$ with total run time of $20 \mathrm{~min}$. Injection port, interface and ion source were kept at $250{ }^{\circ} \mathrm{C}, 300{ }^{\circ} \mathrm{C}$ and $230{ }^{\circ} \mathrm{C}$, respectively. Helium was used as carrier gas at a flow rate of $0.9 \mathrm{~mL} / \mathrm{min}$. 


\section{LC-MS analysis}

Chemical extracts of A taxiformis prepared above were analyzed using 1290 Infinity II UHPLC system (Agilent Technologies) coupled to a high-resolution Impact II Q-TOF mass spectrometer (Bruker Daltonics). Mass spectrometry data were collected in the negative ionization mode in the mass range $\mathrm{m} / \mathrm{z}$ 100-2000 Da, and the data collected were deposited in the MassIVE repository (ID\# MSV000084456). Samples were analyzed using Kinetex ${ }^{\mathrm{TM}} 1.7 \mu \mathrm{m}$ C18 reversed phase UHPLC column $(50 \times 2.1 \mathrm{~mm})$ at a flow rate of $0.5 \mathrm{~mL} / \mathrm{min}$ and the chromatographic separation was achieved using two solvents; solvent $\mathrm{A}$ $\left(\mathrm{H}_{2} \mathrm{O}, 0.1 \%\right.$ formic acid) and solvent $\mathrm{B}(\mathrm{MeCN}, 0.1 \%$ formic acid). The chromatography elution profile was as follows: $5 \%$ solvent B from 0-5 min, linear gradient to $100 \%$ solvent B from $5-20$ min, 100\% solvent B from 20-25 min, linear gradient to 5\% solvent B from 25-26 min, 5\% solvent B from 26-28 min, linear gradient to $100 \%$ solvent B from 28-29 min, 100\% solvent B from 29-33 min, linear gradient to 5\% solvent B from 33-34 min, and 5\% solvent B from 34-35 min.

$\mathrm{MS}^{2}$ and $\mathrm{MS}^{3}$ characterization of molecule 1 (1,1,1,5,5,5-hexabromo-2,4-dione) was achieved by direct infusion into the Bruker amaZon SL ion-trap mass spectrometer in a negative ionization mode. Algal extract was prepared and enriched for $\mathbf{1}$ prior to mass spectrometry-based characterization. Freeze-dried algal biomass $(55 \mathrm{~g})$ was extracted twice with $100 \mathrm{~mL} \mathrm{MeOH}$ by stirring at room temperature for $16 \mathrm{~h}$, extracts pooled, filtered, and concentrated using rotary evaporator. The concentrated extract was resuspended in small volume of hexane:EtOAc $(40: 1)$ before application to a silica gel chromatography column equilibrated in the same solvent. Elution was done with a gradient of hexane:EtOAc $(40: 1 \rightarrow 10: 1 \rightarrow 8: 1 \rightarrow 4: 1 \rightarrow 2: 1)$. The hexane:EtOAc (2:1) fraction containing molecule 1 was concentrated and then infused in to the mass spectrometer at a flow rate of $4 \mu \mathrm{L} / \mathrm{min}$ using a metered peristaltic pump. Signal was allowed to stabilize before isolation of $\mathrm{MS}^{1}$ ion of 572.49 and then fragmented to obtain $\mathrm{MS}^{2}$ ions $m / z 318.74$ and $m / z 250.75$. MS 2 ion $m / z 318.74$ was isolated and fragmented further to obtain $\mathrm{MS}^{3}$ spectra.

\section{Genomic DNA extraction}

DNA from algal samples was extracted following the protocol described in previous study. ${ }^{1}$ Algal biomass samples stored in RNAlater were thawed at $4{ }^{\circ} \mathrm{C}$ and washed twice with TE buffer $(10 \mathrm{~mm}$ Tris- $\mathrm{HCl}(\mathrm{pH}$ 7.5), $1 \mathrm{mM}$ Na-EDTA) to remove excess salts. Biomass was frozen with liquid nitrogen and freeze-dried overnight in a lyophilizer. Dried biomass was ground to fine powder with mortar and pestle using liquid nitrogen. $500 \mathrm{mg}$ of crushed powder was resuspended in $10 \mathrm{~mL}$ of CTAB buffer $(3 \% \mathrm{w} / \mathrm{v}$ cetyltrimethylammonium bromide (CTAB), $1.4 \mathrm{M} \mathrm{NaCl}, 20 \mathrm{mM}$ Na-EDTA, $100 \mathrm{mM}$ Tris- $\mathrm{HCl}$ (pH 8.0), 
$0.2 \%$ polyvinylpolypyrrolidone, $0.2 \% \beta$-mercaptoethanol, and $0.2 \mathrm{mg} / \mathrm{mL}$ proteinase $\mathrm{K}$ ). Samples were incubated at $55^{\circ} \mathrm{C}$ for $2 \mathrm{~h}$ with gentle mixing every $15 \mathrm{~min}$ and then centrifuged at $14,000 \times \mathrm{g}$ for $15 \mathrm{~min}$ at room temperature to remove cellular debris. To the supernatant was added $2 \mathrm{~mL}$ of $5 \mathrm{M}$ Na-acetate $(\mathrm{pH}$ 8.0 ), cooled on ice for $30 \mathrm{~min}$, and centrifuged at $14,000 \times \mathrm{g}$ for $15 \mathrm{~min}$ at $4{ }^{\circ} \mathrm{C}$. The aqueous layer (supernatant) was extracted with equal volume of phenol:chloroform:isoamyl alcohol ((25:24:1) saturated with $10 \mathrm{mM}$ Tris- $\mathrm{HCl}(\mathrm{pH} \mathrm{8.0)}, 1 \mathrm{mM} \mathrm{Na}-E D T A)$ and the mixture was centrifuged at 12,000×g for $5 \mathrm{~min}$ at $4{ }^{\circ} \mathrm{C}$. The supernatant thus obtained was extracted with equal volume of chloroform and then centrifuged at $12,000 \times \mathrm{g}$ for $5 \mathrm{~min}$ at $4{ }^{\circ} \mathrm{C}$. To the supernatant thus obtained was added equal volume of ice-chilled isopropanol, mixed by inverting the tube, and centrifuged at $12,000 \times \mathrm{g}$ for $15 \mathrm{~min}$ at $4{ }^{\circ} \mathrm{C}$. The supernatant was removed and the pellet containing nucleic acids was washed with $75 \%(\mathrm{v} / \mathrm{v})$ ethanol, centrifuged as before, supernatant removed, and the pellet was dried in a speedvac to remove any residual ethanol. The dried pellet was resuspended in $0.5 \mathrm{~mL}$ of $10 \mathrm{mM}$ Tris- $\mathrm{HCl}(\mathrm{pH} 8.0)$ containing $0.6 \mathrm{mg} / \mathrm{mL}$ of RNase A, incubated at room temperature for $1 \mathrm{~h}$ and then incubated overnight at $4{ }^{\circ} \mathrm{C}$ to digest any contaminating RNA. The RNase treated sample was extracted with equal volume of phenol:chloroform:isoamyl alcohol followed by chloroform extraction as described before. Na-acetate ( $\mathrm{pH}$ 5.2) was added to the supernatant to a final concentration of $0.3 \mathrm{M}$ followed by addition of three volumes of ice-chilled ethanol, and then incubated at $-20^{\circ} \mathrm{C}$ for $2 \mathrm{~h}$ to precipitate DNA. The sample was then centrifuged at $16,000 \times \mathrm{g}$ for $20 \mathrm{~min}$ at $4{ }^{\circ} \mathrm{C}$, the pellet washed with $75 \%(\mathrm{v} / \mathrm{v})$ ethanol, centrifuged again, and the pellet was dried in a speedvac. The DNA pellet was resuspended in desired volume of $10 \mathrm{mM}$ Tris- $\mathrm{HCl}(\mathrm{pH} 8.0)$ and the quality of genomic DNA was analyzed by gel electrophoresis and nanodrop.

\section{Phylogenetic analysis}

Phylogenetic assignment of Asparagopsis samples was achieved by PCR amplification and amplicon sequencing of the $18 S$ rRNA gene. Universal primers, as described in literature, (forward primer 566:5' CAGCAGCCGCGGTAATTCC-3' and reverse primer 1200:5'-CCCGTGTTGAGTCAAATTAAGC-3') were used for PCR amplification, and covered variable region v4-v5 of $18 S$ rRNA gene. ${ }^{2}$ Intraspecific relationship of $A$. taxiformis samples were inferred by amplification of mitochondrial marker cox2-cox3 spacer that spans the intergenic region between two conserved gene pair cytochrome oxidase subunit 2 (cox2) and cytochrome oxidase subunit 3 (cox3). Degenerate primers, as described before, (forward primer cox2:5'-GTACCWTCTTTDRGRRKDAAATGTGATGC-3' and reverse primer cox3:5'GGATCTACWAGATGRAAWGGATGTC-3') was used for amplification of cox2-cox3 spacer. ${ }^{3}$ PCR reactions were done in total volume of $25 \mu \mathrm{L}$ and contained $20 \mathrm{ng}$ of genomic DNA, $0.4 \mu \mathrm{M}$ primers, 2.5 $\mathrm{mM}$ dNTPs, $1 \times$ Phusion buffer and 0.5 unit of Phusion-high fidelity DNA polymerase. PCR reactions were 
carried out in a thermocycler using the following program: initial denaturation at $98{ }^{\circ} \mathrm{C}$ for $2 \mathrm{~min}, 33$ cycles of $98{ }^{\circ} \mathrm{C}$ for $30 \mathrm{sec}, 55^{\circ} \mathrm{C}$ for $30 \mathrm{sec}, 72{ }^{\circ} \mathrm{C}$ for $60 \mathrm{sec}$ for $18 S \mathrm{r} R N A$ gene and $72{ }^{\circ} \mathrm{C}$ for $30 \mathrm{sec}$ for cox2cox3 spacer, and final extension at $72{ }^{\circ} \mathrm{C}$ for $10 \mathrm{~min}$. The PCR amplicons were purified using DNA Clean and Concentrator Kit (Zymo Research). An 'A' nucleotide was added to blunt-ends of PCR product using GoTaq polymerase (Promega). The amplicons were then cloned into pGEM-T Easy vector as per manufacturer's instructions followed by transformation into Escherichia coli (DH5 $\alpha)$ under appropriate antibiotic selection. Individual colonies were selected for growth and plasmid DNA extracted using standard miniprep protocols followed by Sanger sequencing of the inserts. Sequences were deposited in the GenBank database.

GenBank accession numbers for algal $18 S \mathrm{r} R N A$ region are as follows:

Guam (MN547333)

California (MN547332)

Hawaii (MN547334)

Florida (MN547336)

Fiji (MN547335)

GenBank accession numbers for algal $\operatorname{cox} 2-\operatorname{cox} 3$ spacer are as follows:

Guam (MN563722)

California (MN563723)

Hawaii (MN563724)

Florida (MN563725)

Fiji (MN563726)

Phylogenetic tree was constructed using the $\operatorname{cox} 2-\cos 3$ spacer sequence information of five $A$. taxiformis samples from our study and sequences of other $A$. taxiformis samples available in the GenBank database. Tree was constructed in MEGA7 using default parameters of Maximum Likelihood method based on Tamura-Nei model..$^{3,4}$ 


\section{Preparation of algal protein extract}

Algal biomass for protein extract preparation were harvested, snap frozen in liquid nitrogen and stored at $80{ }^{\circ} \mathrm{C}$ until further use. $100 \mathrm{mg}$ of frozen biomass was added to $2 \mathrm{~mL}$ safe-lock tube containing $0.8 \mathrm{~mL}$ of homogenization buffer (100 mM HEPES-Na (pH 7.6), 10\% glycerol) and $1.1 \mathrm{~g}$ of $1.4 \mathrm{~mm}$ ceramic beads. Samples were homogenized at $4{ }^{\circ} \mathrm{C}$ using a Bullet Blender Storm 24 (Next Advance) for 10 min at a power of ' 10 '. The lysate thus obtained was centrifuged at $9,000 \times \mathrm{g}$ for $10 \mathrm{~min}$ to obtain the total protein extract as the supernatant. Typical protein preparation utilized 400-600 mg of total algal biomass which resulted in 2-3 $\mathrm{mL}$ of supernatant. The $9,000 \times \mathrm{g}$ supernatants were pooled and divided equally into two aliquots and then dialyzed separately in dialysis buffer A (100 mM HEPES-Na (pH 7.6), 10\% glycerol, $50 \mathrm{mM} \mathrm{KCl}$ and $10 \mu \mathrm{M}$ sodium orthovanadate) to yield holo-enzyme extract and in buffer B (100 mM HEPES-Na (pH 7.6), $10 \%$ glycerol, $50 \mathrm{mM} \mathrm{KCl}$ and $1 \mathrm{mM} \mathrm{Na-EDTA)} \mathrm{to} \mathrm{yield} \mathrm{apo-enzyme} \mathrm{extract.} \mathrm{Dialysis} \mathrm{with} \mathrm{Na-EDTA}$ will result in apo-enzyme extract as EDTA is known to form stable complex with vanadate. ${ }^{5}$ Dialysis was done using Slide-A-Lyzer dialysis cassette (3.5K MWCO, $3 \mathrm{~mL}$ ) overnight at $4{ }^{\circ} \mathrm{C}$ in $1 \mathrm{~L}$ of dialysis buffer A or B. Dialysis was repeated in fresh buffer for another $4 \mathrm{~h}$ before using the protein extract for enzyme assays.

\section{Enzyme assays for bromoform production}

Enzyme assays were typically done in $1 \mathrm{~mL}$ total volume at $30^{\circ} \mathrm{C}$ and contained $100 \mathrm{mM}$ HEPES-Na (pH 7.6), $50 \mathrm{mM} \mathrm{KBr}, 10 \mu \mathrm{M}$ sodium orthovanadate, $1 \mathrm{mM}$ substrate $(\mathbf{5}$ or $\mathbf{6})$ and $50 \mu \mathrm{g}$ of protein extract or 1 $\mu \mathrm{M}$ recombinant protein. Reactions were initiated by addition of $1 \mu \mathrm{L}$ of $1 \mathrm{M} \mathrm{H}_{2} \mathrm{O}_{2}$, and same volume of $\mathrm{H}_{2} \mathrm{O}_{2}$ was added every $10 \mathrm{~min}$ for a total reaction time of $90 \mathrm{~min}$. Assay with apo-enzyme extract was done in absence of sodium orthovanadate. Reactions were quenched by addition of $1 \mathrm{~mL}$ of GC-grade diethyl ether and $100 \mu \mathrm{L}$ brine. Reaction products were then extracted by vigorous agitation on a vortex mixer, centrifuged at $1,500 \times \mathrm{g}$ to obtain phase separation, and the top organic layer removed. Extraction was repeated once again with $1 \mathrm{~mL}$ of diethyl ether, organic extracts pooled, concentrated using rotary evaporator, and aliquots of extracts were analyzed by GC-MS using conditions described above.

\section{RNA Isolation}

Total RNAs from algal sample were isolated as reported before. ${ }^{6}$ Algal biomass stored in RNAlater was washed with TE buffer as described earlier and then frozen in liquid nitrogen. $200 \mathrm{mg}$ of frozen tissue was pulverized in liquid nitrogen using mortar and pestle. Frozen powder was added to $1 \mathrm{~mL}$ of TRIzol (Invitrogen) and mixed briefly using vortex to obtain homogenous solution. Sample incubated at room 
temperature for $5 \mathrm{~min}$, mixed again, and centrifuged at $10,000 \mathrm{x}$ g for $5 \mathrm{~min}$ at room temperature to pellet cell debris. Centrifugation repeated when necessary to obtain the clear supernatant. The supernatant mixed with $0.2 \mathrm{~mL}$ of chloroform, mixed using vortex, incubated at room temperature for $5 \mathrm{~min}$, and then centrifuged at $12,000 \times \mathrm{g}$ for $15 \mathrm{~min}$ at $4{ }^{\circ} \mathrm{C}$ to obtain phase separation. The supernatant (aqueous phase) containing RNA was carefully removed to a new tube, $0.5 \mathrm{~mL}$ of isopropanol added, and mixed by invert mixing. Sample incubated at room temperature for $10 \mathrm{~min}$ followed by centrifugation at $12,000 \times \mathrm{g}$ for 15 min at $4{ }^{\circ} \mathrm{C}$ to pellet RNA. The supernatant was removed, RNA pellet washed with $1 \mathrm{~mL}$ of $75 \%$ ethanol by inverting mixing and centrifuged at $12,000 \times \mathrm{g}$ for $15 \mathrm{~min}$ at $4{ }^{\circ} \mathrm{C}$. The supernatant was removed, RNA

pellet was partially dried using speed vacuum, and further processed to ensure removal of contaminating polysaccharides. This was achieved by resuspension of the RNA pellet in $2 \mathrm{M} \mathrm{LiCl}$ at room temperature followed by centrifugation at $12,000 \times \mathrm{g}$ for $15 \mathrm{~min}$ at $4{ }^{\circ} \mathrm{C}$. This process was repeated until the size of the RNA pellet did not reduce further. The RNA pellet was then dissolved in $0.5 \mathrm{~mL}$ TE buffer, extracted with equal volume of phenol/chloroform/isoamyl alcohol ((25:24:1) saturated with $10 \mathrm{mM}$ Tris- $\mathrm{HCl}$ (pH 8.0), 1 mM Na-EDTA), and centrifuged for phase separation. The aqueous phase was further extracted with equal volume of chloroform and centrifuged at $12,000 \times \mathrm{g}$ for $15 \mathrm{~min}$ at $4{ }^{\circ} \mathrm{C}$. The supernatant containing RNA was treated with 0.1 volume of $3 \mathrm{M} \mathrm{Na}$-acetate (pH 5.2) and 2.5 volumes of ethanol and incubated overnight at $-80{ }^{\circ} \mathrm{C}$ to precipitate RNA. The sample was centrifuged at $12,000 \times \mathrm{g}$ for $15 \mathrm{~min}$ at $4{ }^{\circ} \mathrm{C}$, the supernatant removed, and the RNA pellet was washed with $75 \%(\mathrm{v} / \mathrm{v})$ ethanol. The pellet was dried in a speedvac followed by resuspension in desired volume of nuclease free water. The isolated total RNA was treated with DNA-free ${ }^{\mathrm{TM}}$ DNA removal kit (Invitrogen) to remove any contaminating genomic DNA. Several micrograms of good quality RNA were obtained with $\mathrm{A}_{260} / \mathrm{A}_{280}$ and $\mathrm{A}_{260} / \mathrm{A}_{230}$ values greater than 2.0. Analysis of total RNA by agarose gel did not show any genomic DNA contamination and was further confirmed by reverse transcriptase-PCR (RT-PCR) analysis.

\section{Transcriptome sequencing, assembly and analysis}

Short-gun sequencing was performed using an Illumina HiSeq 2000 sequencer with a 2350 bp inserts and 125 bp paired-end runs, or an Illumina NovaSeq sequencer with a $\sim 50$ bp inserts and 150 bp paired-end runs at the Huntsman Cancer Institute's High Throughput Genomics Center at the University of Utah. Raw reads were trimmed and adaptors removed by Trimmomatic- $0.39^{7}$ with parameters (PE -phred33 ILLUMINACLIP TruSeq3-PE-2.fa:2:30:10 LEADING:3 TRAILING:3 SLIDINGWINDOW:4:15 MINLEN:(80 or 150)). The trimmed reads were merged using BBMerge ${ }^{8}$ and then assembled using rnaSPAdes $(\text { mink }=21 \text { maxk }=121 \text { step }=10)^{9}$ with standard parameters in the Center for High Performance Computing at the University of Utah. 
The eukaryotic genes predicted by AUGUSTUS were used as reference genes, trimmed reads of each sample were multi-mapped to the reference using Salmon6 with parameters (salmon index - $\mathrm{t}-\mathrm{i}$ index -k 31; salmon quant --index --validateMappings --libType A --dumpEq -r). The identical predicted genes from both samples were hierarchically clustered into clusters, and then cluster count was summarized using Corset 1.047 according to shared reads information with parameters (-f true -g -n -i salmon_eq_classes). Transcript abundance of each gene was estimated using EdgeR8 by normalized counts per million (cpm).

\section{RT-PCR and cloning}

All genes from $A$. taxiformis that are characterized in this study were cloned using cDNA as template. GeneBank accession numbers for A. taxiformis ACP and FabH are AOM65890.1 and AOM66007.1, respectively. The cDNA was prepared using SuperScript IV first-strand synthesis system (Thermo Fisher). The first step of cDNA synthesis reaction was set up in $13 \mu \mathrm{L}$ reaction volume containing $600 \mathrm{ng}$ of total RNA, $1 \mu \mathrm{L}$ of $10 \mathrm{mM}$ dNTP mix, and $1 \mu \mathrm{L}$ of $50 \mu \mathrm{M}$ oligo $\mathrm{dT}_{20}$ primer. The reaction was incubated at 65 ${ }^{\circ} \mathrm{C}$ for $5 \mathrm{~min}$, incubated in ice for $2 \mathrm{~min}$, and then added to a tube containing $4 \mu \mathrm{L}$ of $5 \mathrm{x}$ superscript buffer, $1 \mu \mathrm{L}$ of $100 \mathrm{mM}$ DTT, $1 \mu \mathrm{L}$ of ribonuclease inhibitor, and 200 unit of Superscript IV enzyme. The reaction mix was incubated at $55^{\circ} \mathrm{C}$ for $10 \mathrm{~min}$ followed by heat inactivation at $80{ }^{\circ} \mathrm{C}$ for $10 \mathrm{~min}$. The reaction mix was further treated with 2 unit of RNase $\mathrm{H}$ by incubating at $37^{\circ} \mathrm{C}$ for $20 \mathrm{~min}$. The product $(3 \mu \mathrm{L})$ from cDNA synthesis reaction was used as template for PCR with high fidelity Phusion DNA polymerase and gene specific primers. Negative control reaction for RT-PCR was identical to other reactions except omission of the reverse transcriptase enzyme. RT-PCR products were cleaned with DNA clean and concentrator kit, nucleotide A added using GoTaq DNA polymerase, and then cloned into pGEM-T Easy vector as described above followed by transformation into E. coli $\mathrm{DH} 5 \alpha$, colony selection and miniprep. The pGEM-T constructs were used as template for cloning into desired expression vectors.

\section{Cloning and protein purification}

For characterization of C. crispus VHPOs ${ }^{10}$, three of the five VHPOs with highest sequence identity to $A$. taxiformis Mbb4 protein were chosen, gene fragments optimized for expression in E.coli were synthesized (Twist Biosciences), and cloned into pGEM-T Easy vector. The $C c$ VHPOs were arbitrarily numbered. The GenBank accession numbers of CcVHPO1, CcVHPO2 and CcVHPO3 are XP_005714237.1, XP_005719435.1 and XP_005710894.1, respectively. The pGEM-T gene construct for each gene was used as a template for PCR with high fidelity Phusion DNA polymerase. The MatB gene construct as described in previous study ${ }^{11}$ was a gift from Dr. Keatinge-Clay (UT Austin) and was used as a template for cloning 
into pET28MBP vector. The PCR amplicons for each gene were cloned into expression vector using NEBuilder HiFi DNA Assembly master mix following the manufacturer's instructions. The E. coli expression constructs used in this study are listed in Supplementary Table 3. The expression constructs for algal genes were transformed into E. coli (Rosetta) cells, whereas MatB and Sfp constructs were transformed into E. coli (BL21DE3) cells. In a typical protein expression experiment, 10-mL overnight culture was used to inoculate two 1-liter terrific broth media (1-liter for MatB and Sfp) containing appropriate antibiotic (kanamycin at $50 \mathrm{mg} / \mathrm{L}$, ampicillin at $100 \mathrm{mg} / \mathrm{L}$ and chloramphenicol at $34 \mathrm{mg} / \mathrm{L}$ ). $E$. coli cultures were grown at $30{ }^{\circ} \mathrm{C}$ with shaking at $180 \mathrm{rpm}$ until $\mathrm{OD}_{600}$ of 0.8 , cultures cooled down to 18 ${ }^{\circ} \mathrm{C}$, incubated for another $1 \mathrm{~h}$ at $18{ }^{\circ} \mathrm{C}$, and then induced with $0.3 \mathrm{mM}$ IPTG. All subsequent steps for purification were done on ice or at $4{ }^{\circ} \mathrm{C}$ using the standard protocol unless mentioned otherwise. Cultures were harvested by centrifugation, pellet resuspended in lysis buffer $(20 \mathrm{mM}$ Tris pH 8.0, $500 \mathrm{mM} \mathrm{NaCl}, 1$ mM EDTA), cells lysed by sonication, centrifuged at 30,000×g for $40 \mathrm{~min}$, and the supernatant loaded into 5 mL His-Trap Ni-NTA column using AKTA Prime FPLC system. Column was washed extensively with wash buffer (20 mM Tris pH 8.0, $500 \mathrm{mM} \mathrm{NaCl}, 30 \mathrm{mM}$ imidazole) and protein eluted using linear gradient to $100 \%$ elution buffer ( $20 \mathrm{mM}$ Tris $\mathrm{pH} 8.0,500 \mathrm{mM} \mathrm{NaCl}, 250 \mathrm{mM}$ imidazole) for a total volume of 40 $\mathrm{mL}$. Purity of eluant fractions were checked using SDS-PAGE, and fractions containing protein of interest were pooled and concentrated to $2.5 \mathrm{~mL}$ using Amicon centrifugal filters. Protein samples were desalted using PD-10 column and eluted in storage buffer (20 mM HEPES pH 7.5, $50 \mathrm{mM} \mathrm{KCl}, 10 \%$ glycerol). Purified proteins were stored as small aliquots at $-80{ }^{\circ} \mathrm{C}$ and fresh aliquots of each protein were used for enzyme assays. None of the proteins characterized in this study showed loss of activity during storage at $80{ }^{\circ} \mathrm{C}$ for several months.

\section{Monocholorodimedone (MCD) Assay}

Halogenation activity of Mbb enzymes and $C c$ VHPOs were determined using MCD assay. ${ }^{5}$ Reactions were performed in a quartz cuvette at $25{ }^{\circ} \mathrm{C}$, and the decrease in absorbance of MCD substrate were monitored spectrophotometrically at $290 \mathrm{~nm}$ every $30 \mathrm{sec}$ for $15 \mathrm{~min}$ using NanoDrop OneC UV-Vis spectrophotometer. Reactions were initiated by adding the recombinant enzymes in a $0.75 \mathrm{~mL}$ total reaction volume containing $100 \mathrm{mM}$ Na-citrate ( $\mathrm{pH}$ 6.5), $100 \mathrm{mM} \mathrm{KBr}$ or $\mathrm{KCl}, 100 \mu \mathrm{M} \mathrm{MCD}, 10 \mu \mathrm{M}$ sodium orthovanadate, and $2 \mathrm{mM}$ hydrogen peroxide. Assays were done in triplicate for total of six enzymes at a varied concentration, Mbb1-250 nM, Mbb3-1 $\mu \mathrm{M}$, Mbb4-100 nM, CcVHPO1-50 nM, CcVHPO2-50 nM, and $C c$ VHPO3-250 nM. Enzyme concentrations used in the assays were empirically determined due to the difference in the activity of individual enzymes. 
Synthesis of heptane-2,4,6-trione (6)

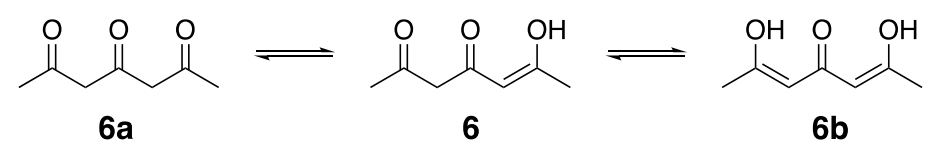

6 was prepared as described before. ${ }^{12}$ Commercial 2,6-dimethyl- $\gamma$-pyrone (500 mg, $\left.4.03 \mathrm{mmol}\right)$ was dissolved in $2.5 \mathrm{~mL}$ ethanol and treated with $0.5 \mathrm{~mL}$ of $16 \mathrm{M} \mathrm{NaOH}$. The reaction mixture was stirred at $60{ }^{\circ} \mathrm{C}$ for $5 \mathrm{~h}$, and then heated at $100^{\circ} \mathrm{C}$ for another $1 \mathrm{~h}$. Precipitate formed during the reaction was filtered and washed with diethyl ether. The crystals were dissolved in water followed by the addition of $5 \mathrm{~mL}$ of 3 $\mathrm{M} \mathrm{HCl}$ solution. The aqueous phase was extracted thrice with diethyl ether. The organic layer was dried with anhydrous Na-sulfate and concentrated under vacuum which afforded the target compound as a yellow solid. Tautomeric equilibrium of product in chloroform- $d$ was $68.8 \% \mathbf{6}, 24.6 \% \mathbf{6 b}$ and $6.6 \% \mathbf{6 a} .{ }^{1} \mathbf{H}-\mathbf{N M R}$ $\left(400 \mathrm{MHz}, \mathrm{CDCl}_{3}\right) \delta 15.21(\mathrm{~s}, 1 \mathrm{H}), 14.18(\mathrm{~s}, 1 \mathrm{H}), 5.56(\mathrm{~s}, 1 \mathrm{H}), 5.14(\mathrm{~s}, 1 \mathrm{H}), \delta 3.70(\mathrm{~s}, 4 \mathrm{H}), \delta 3.40(\mathrm{~s}, 2 \mathrm{H})$, $2.25(\mathrm{~s}, 6 \mathrm{H}), 2.08(\mathrm{~s}, 3 \mathrm{H}), 1.98(\mathrm{~s}, 3 \mathrm{H}) .{ }^{13} \mathrm{C}-\mathrm{NMR}\left(101 \mathrm{MHz}, \mathrm{CDCl}_{3}\right) \delta$ 202.07, 193.88, 191.23, 187.02, $178.65,101.21,98.76,57.85,54.12,30.52,24.76,21.99$.

\section{Synthesis of malonyl-CoA}

Previously described enzyme MatB was used to synthesize malonyl-CoA. ${ }^{11}$ MatB enzyme assay was performed in a $100 \mu \mathrm{L}$ reaction volume containing $100 \mathrm{mM}$ HEPES-Na (pH 7.6), $20 \mathrm{mM} \mathrm{MgCl}, 20 \mathrm{mM}$ Na-malonate, $20 \mathrm{mM}$ ATP, $5 \mathrm{mM}$ TCEP, $5 \mathrm{mM}$ CoA-SH, 15\% (v/v) glycerol and $5 \mu \mathrm{M}$ MatB. Reaction was incubated at $30^{\circ} \mathrm{C}$ for $23 \mathrm{~h}$. Control reaction omitted MatB. An aliquot of reaction was quenched with equal volume of solvent ( $\mathrm{MeOH}+1 \%$ trifluoroacetic acid (TFA) for HPLC analysis and MeCN $+0.2 \%$ formic acid for LC-MS/MS analysis), precipitate removed by centrifugation, and supernatant analyzed by HPLC system and LC-MS/MS using Phenomenex Luna C8 column $5 \mu \mathrm{m}(250 \times 4.6 \mathrm{~mm})$ column. LCMS/MS analysis was done using Agilent 1290 Infinity II UHPLC system coupled to a high-resolution Bruker Impact II Q-TOF mass spectrometer. MS data were collected in the positive ionization mode from $m / z$ 100-2000 Da. HPLC analysis used solvent A $\left(100 \% \mathrm{H}_{2} \mathrm{O}, 0.1 \%\right.$ TFA) and solvent $\mathrm{B}(100 \% \mathrm{MeOH}$, $0.1 \%$ TFA). LC-MS analysis used solvent A $\left(100 \% \mathrm{H}_{2} \mathrm{O}, 0.1 \%\right.$ formic acid) and solvent $\mathrm{B}(100 \% \mathrm{MeCN}$, $0.1 \%$ formic acid). Samples were analyzed at a flow rate of $0.5 \mathrm{~mL} / \mathrm{min}$, and elution profile for both HPLC and LC-MS/MS analysis were: $5 \%$ solvent B from 0-3 min, linear gradient to $25 \%$ solvent B from 3-8 min, linear gradient to 50\% solvent B from 8-20 min, linear gradient to $100 \%$ solvent B from $20-23$ min, $100 \%$ solvent B from $23-26$ min, linear gradient to $5 \%$ solvent B from $26-27$ min, $5 \%$ solvent B from 27-28 min, linear gradient to $100 \%$ solvent B from $28-29 \mathrm{~min}, 100 \%$ solvent B from $29-30 \mathrm{~min}$, and linear gradient to 5\% solvent B from 30-31 min. 


\section{Synthesis of malonyl-S-ACP}

Malonyl-CoA synthesized above was used as the substrate to modify ACP using Sfp enzyme. ${ }^{13}$ Assays were performed at $30{ }^{\circ} \mathrm{C}$ for $3 \mathrm{~h}$ in a $100 \mu \mathrm{L}$ total reaction volume containing $100 \mathrm{mM}$ HEPES-Na (pH 7.6), $500 \mu \mathrm{M} \mathrm{ACP}, 50 \mu \mathrm{L}$ reaction product from MatB assay, $10 \mathrm{mM} \mathrm{MgCl}_{2}$, and $2 \mu \mathrm{M}$ Sfp. Control reaction omitted the Sfp enzyme. An aliquot of reaction was quenched by adding equal volume of $\mathrm{MeCN}$ $+0.2 \%$ formic acid, precipitate observed was removed by centrifugation, and supernatant was analyzed by LC-MS/MS using Aeris $3.6 \mu \mathrm{m}$ widepore XB-C18 $(200 \AA 250 \times 4.6 \mathrm{~mm})$ column at a flow rate of 0.5 $\mathrm{mL} / \mathrm{min}$. MS data were collected in the positive ionization mode from $\mathrm{m} / z$ 100-2000 Da, and data analysis for ACP proteins (with or without acyl-groups) were done following the method described in previous study. ${ }^{14}$ The elution profile for LC-MS/MS analysis was as follows: 5\% solvent B from 0-5 min, linear gradient to $70 \%$ solvent B from 5-30 min, linear gradient to $95 \%$ solvent B from 30-31 min, 95\% solvent B from 31-35 min, linear gradient to 5\% solvent B from 35-36 min, 5\% solvent B from 36-38 min, linear gradient to $95 \%$ solvent B from $38-39 \mathrm{~min}, 95 \%$ solvent B from $39-42 \mathrm{~min}$, linear gradient to $5 \%$ solvent B from $42-43 \mathrm{~min}$, and 5\% solvent $\mathrm{B}$ from $43-46 \mathrm{~min}$.

\section{Synthesis of acetoacetyl-S-ACP (8)}

Synthesis of 8 was performed at $30^{\circ} \mathrm{C}$ for $3 \mathrm{~h}$ in a $100 \mu \mathrm{L}$ total reaction volume containing $100 \mathrm{mM} \mathrm{HEPES}$ $\mathrm{Na}$ (pH 7.6), $50 \mu \mathrm{L}$ reaction product from Sfp loading assay, $1 \mathrm{mM}$ acetyl-CoA, $1 \mathrm{mM}$ TCEP and $2 \mu \mathrm{M}$ $\mathrm{FabH}$. After $3 \mathrm{~h}$ incubation, an aliquot of reaction was quenched with equal volume of $\mathrm{MeCN}+0.2 \%$ formic acid, precipitate removed by centrifugation and analyzed by LC-MS/MS using the procedure described above for malonyl-S-ACP.

\section{Preparative scale synthesis of 8 and enzyme assay}

$2 \times 2.5 \mathrm{~mL}$ assays for synthesis of malonyl-CoA were set up as described above. After incubation at $30{ }^{\circ} \mathrm{C}$ for $23 \mathrm{~h}$, both samples were pooled, and reaction product was used to set up $4 \times 2.5 \mathrm{~mL}$ assays for synthesis of malonyl-S-ACP using the reaction conditions described above. After incubation of Sfp loading reaction at $30^{\circ} \mathrm{C}$ for $3 \mathrm{~h}$, precipitate was removed by centrifugation at $1500 \times \mathrm{g}$ for $10 \mathrm{~min}$, and the supernatant was used to set up $8 \times 2.5 \mathrm{~mL}$ assays with the FabH enzyme. Reaction conditions for synthesis of acetoacetyl-SACP were same as described above. After incubation at $30^{\circ} \mathrm{C}$ for $3 \mathrm{~h}$, samples were pooled, centrifuged, and the supernatant was concentrated to $2.5 \mathrm{~mL}$ using Amicon centrifugal filters ( $3 \mathrm{kDa} \mathrm{MWCO}$ ). Concentrated sample was loaded onto a desalting PD-10 column, and acetoacetyl-S-ACP was eluted using the buffer $20 \mathrm{mM}$ HEPES-Na (pH 7.5), $50 \mathrm{mM} \mathrm{KCl,} \mathrm{10 \%} \mathrm{glycerol.} \mathrm{Aliquots} \mathrm{of} \mathrm{acetoacetyl-S-ACP} \mathrm{were}$ 
stored at $-80^{\circ} \mathrm{C}$. Production of malonyl-CoA, malonyl-S-ACP and acetoacetyl-S-ACP in each reaction step was verified using LC-MS/MS. Enzyme assays for bromoform synthesis were performed at $30^{\circ} \mathrm{C}$ for $1.5 \mathrm{~h}$ in a $1 \mathrm{~mL}$ reaction volume containing $100 \mathrm{mM}$ HEPES-Na (pH 7.6), $50 \mathrm{mM} \mathrm{KBr}, 10 \mu \mathrm{M}$ sodium orthovanadate, $0.67 \mathrm{mM}$ acetoacetyl-S-ACP and $1 \mu \mathrm{M}$ Mbb1 or Mbb4 enzymes. Reactions were initiated by addition of $1 \mu \mathrm{L}$ of $1 \mathrm{M} \mathrm{H}_{2} \mathrm{O}_{2} \cdot \mathrm{H}_{2} \mathrm{O}_{2}$ was replenished by adding $1 \mu \mathrm{L}$ of $1 \mathrm{M} \mathrm{H}_{2} \mathrm{O}_{2}$ after every 10 min through the course of reaction. After $90 \mathrm{~min}$, reactions were quenched by addition of equal volume of diethyl ether and $100 \mu \mathrm{L}$ brine. Reactions were extracted by vigorous agitation, centrifuged at $1,500 \times \mathrm{g}$ for $10 \mathrm{~min}$ and the top organic layer removed. Extraction was repeated thrice. Organics extracts were pooled, concentrated, and $10 \mu \mathrm{L}$ of concentrated extract was analyzed by GC-MS using manual injection using the conditions described above.

\section{Metagenome sequencing, assembly, binning and annotation.}

Short-gun sequencing was performed using an Illumina NovaSeq sequencer with a $\sim 450$ bp inserts and 150 bp paired-end runs at the Huntsman Cancer Institute's High Throughput Genomics Center at the University of Utah. Raw reads were trimmed and adaptors removed by Trimmomatic- $0.39^{7}$ with parameters (PE phred33 ILLUMINACLIP TruSeq3-PE-2.fa:2:30:10 LEADING:3 TRAILING:3 SLIDINGWINDOW:4:15 MINLEN:150). The trimmed reads were merged using BBMerge ${ }^{8}$ and then assembled using metaSPADES (mink $=21 \operatorname{maxk}=121 \mathrm{step}=10)^{9}$ with standard parameters in the Center for High Performance Computing at the University of Utah. Bacterial contigs were binned out of metagenome assembly using Autometa. ${ }^{15}$ The eukaryotic contigs were annotated using AUGUSTUS ${ }^{16}$ with transcriptome assembly as training data.

\section{Quantitative RT-PCR}

The total RNA from each sample were isolated and cDNA synthesized as above. The product from cDNA synthesis reaction was diluted five-fold in nuclease free water and $3 \mu \mathrm{L}$ was used as template in a $20 \mu \mathrm{L}$ PCR reaction containing $10 \mu \mathrm{L}$ of PowerUp SYBR green master mix (ThermoFisher) and $0.5 \mu \mathrm{M}$ primers. The qRT-PCR reactions were carried out on a StepOnePlus Real-Time PCR system (Applied Biosystems) using following program: initial denaturation at $95^{\circ} \mathrm{C}$ for $2 \mathrm{~min}, 40$ cycles of $\left(95^{\circ} \mathrm{C}\right.$ for $15 \mathrm{sec}, 55^{\circ} \mathrm{C}$ for $15 \mathrm{sec}$ and $72{ }^{\circ} \mathrm{C}$ for $60 \mathrm{sec}$. Expression level for each gene were calculated relative to actin gene using the $2^{-\Delta \Delta \mathrm{CT}}$ method. ${ }^{17}$ Primers used for qRT-PCR are listed on supplementary Table 4. 


\section{Cloning of $y n o 1, m b b 2$ and $C c N O X(C c m b b 2)$ in yeast expression plasmids}

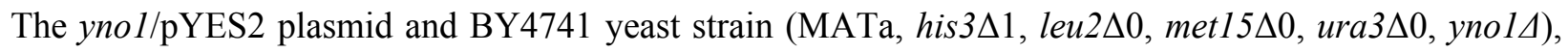
which has a deletion of ynol gene, was a gift from Reddi laboratory at Georgia Tech. Synthetic clones for $m b b 2$ and $C c N O X$ with sequences optimized for expression in yeast were obtained commercially. All genes, $y n o 1, m b b 2$, and $C c N O X$ (Ccmbb2), were amplified using high fidelity Phusion DNA polymerase and PCR amplicons were cloned into pESC-URA expression vector using NotI and SpeI restriction sites. Gene constructs were transformed into ynold yeast strain using standard lithium acetate protocol. ${ }^{18}$ Transformants were selected and patches of positive colonies were maintained on synthetic dropout medium (SC-URA) supplemented with $2 \%$ glucose.

\section{Dihydroethidium (DHE) Assay}

Reactive oxygen species production by yeast cells were measured using DHE as a fluorescent probe and following the methodology as described before. ${ }^{19}$ Yeast cultures were maintained in SC-URA supplemented with $2 \%$ raffinose. Triplicate cultures for each gene constructs were used for DHE assay. Several time points and galactose concentration were screened to determine optimal signal for DHE assay. In brief, $25 \mu \mathrm{L}$ of overnight cultures was used to inoculate $5 \mathrm{~mL}$ of media containing $10 \%$ galactose. The cultures were grown at $30^{\circ} \mathrm{C}$ by shaking at $200 \mathrm{rpm}$ for $43 \mathrm{~h}$, harvested by centrifugation, washed, and resuspended in distilled water. Cells corresponding to $6.25 \mathrm{OD}_{600}$ units were harvested by centrifugation at $6,000 \mathrm{x} g$ and washed three times with PBS buffer. Cells were resuspended in $300 \mu \mathrm{L}$ PBS buffer, DHE added to final concentration of $10 \mu \mathrm{M}$, and then incubated in dark at $30^{\circ} \mathrm{C}$ for $10 \mathrm{~min}$ with invert mixing every two min. After incubation, cells were harvested by centrifugation, washed at least three times with PBS buffer, pellet resuspended in $300 \mu \mathrm{L}$ PBS buffer, $100 \mu \mathrm{L}$ of cell suspension aliquoted to black microwell plate, and fluorescence measured using Biotek Synergy Mx microplate reader with an excitation wavelength of $518 \mathrm{~nm}$ and an emission wavelength of $605 \mathrm{~nm}$. 


\section{SUPPLEMENTARY FIGURES}

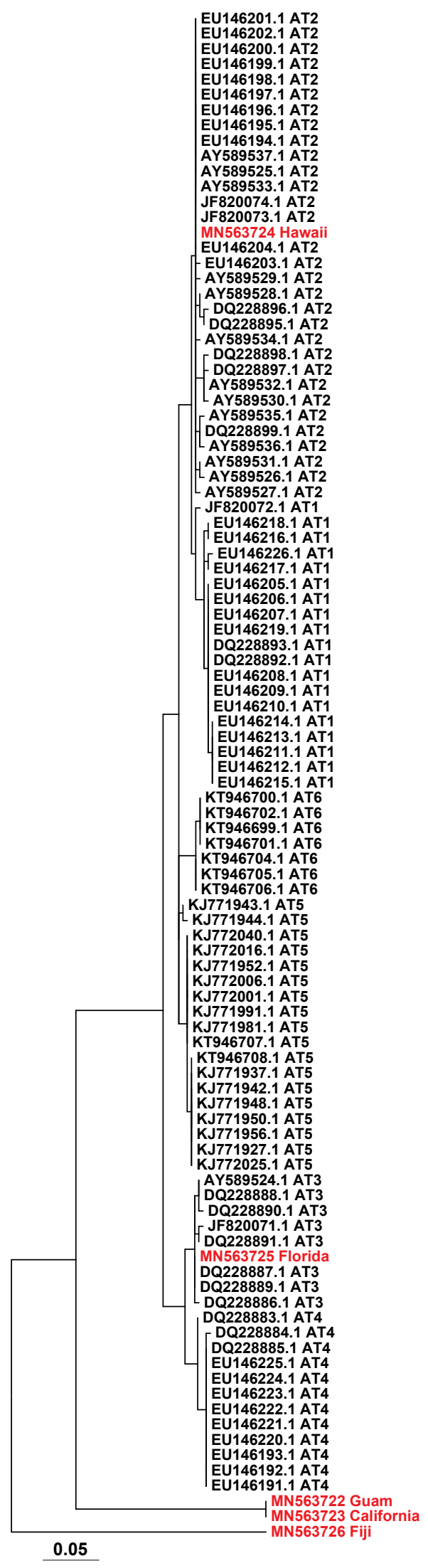

Figure S1: Maximum Likelihood phylogenetic tree of Asparagopsis taxiformis using cox2-cox3 spacer. GenBank accession number followed by lineage information is shown for all cox2-cox3 spacer sequences. Samples from this study are highlighted in red. The evolutionary history was inferred by using the Maximum Likelihood method based on the Tamura-Nei model. ${ }^{4}$ The tree with the highest $\log$ likelihood $(-1151.26)$ is shown. Initial tree(s) for the heuristic search were obtained automatically by applying Neighbor-Join and BioNJ algorithms to a matrix of pairwise distances estimated using the Maximum Composite Likelihood ${ }^{10}$ approach, and then selecting the topology with superior log likelihood value. The tree is drawn to scale, with branch lengths measured in the number of substitutions per site. The analysis involved 100 nucleotide sequences. All positions containing gaps and missing data were eliminated. There was a total of 267 positions in the final dataset. Evolutionary analyses were conducted in MEGA7. ${ }^{20}$ 


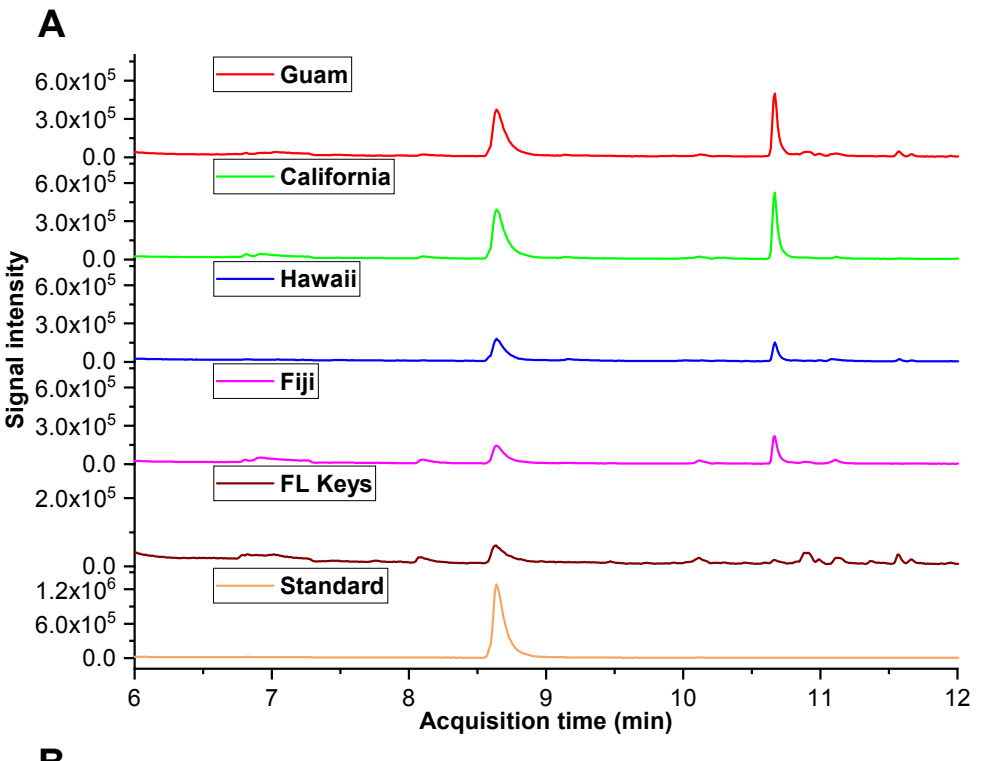

B

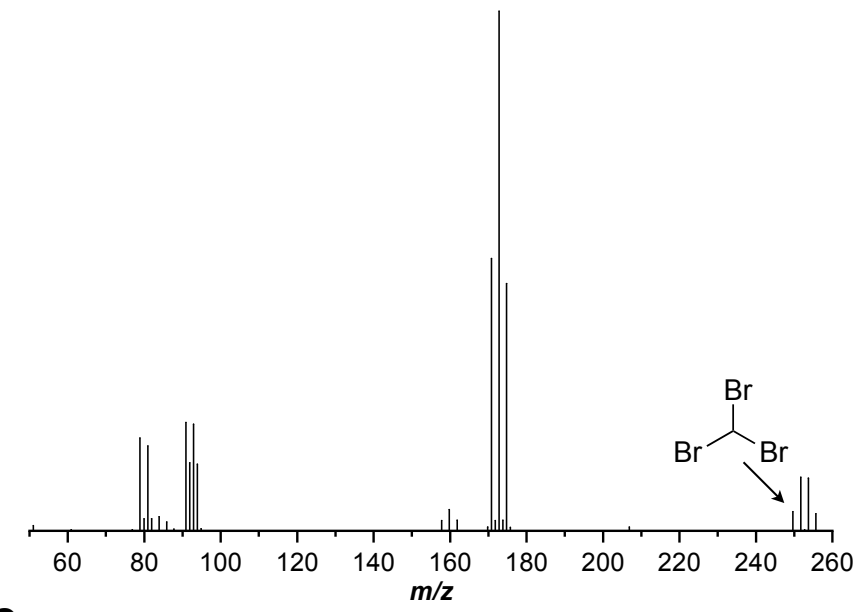

C

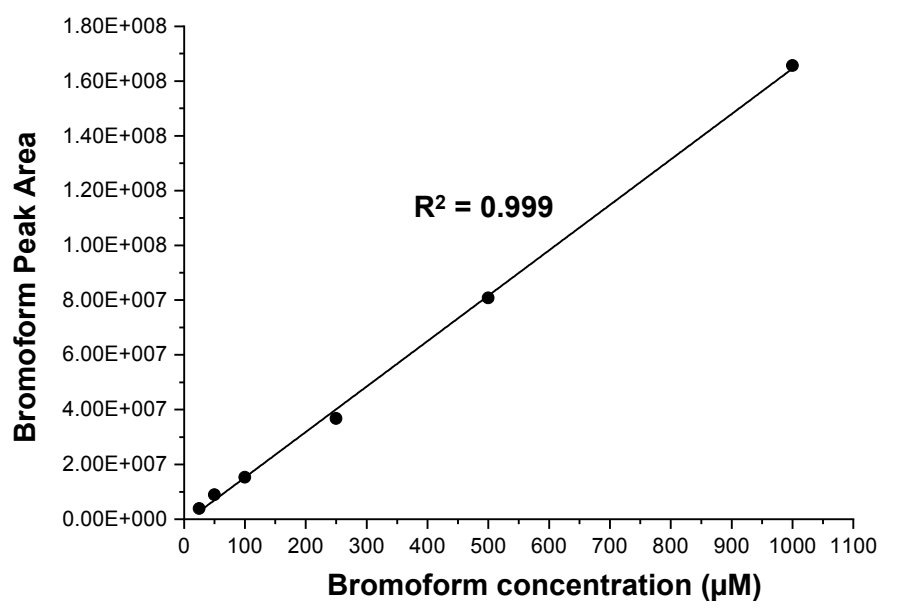

Figure S2: Bromoform production in red macroalga Asparagopsis taxiformis. (A) GC-MS chromatograms for $\mathrm{MeOH}$ extracts demonstrating bromoform production by $A$. taxiformis in geographically disperse samples. (B) MS spectrum of bromoform. Arrow corresponds to monoisotopic ion. (C) Calibration curve generated based on GC-MS analysis of different concentrations of bromoform standard. $25 \mathrm{mg}$ freeze dried algal biomass for each sample was soaked in $625 \mu \mathrm{L}$ $\mathrm{MeOH}$ for several hours, metabolites extracted using vortex mixer, and then centrifuged. The supernatant $(\mathrm{MeOH}$ extracts) was diluted 25-fold in DCM and $1 \mu \mathrm{L}$ was analyzed by GC-MS. Bromoform peak area for each sample was determined and then used for quantification using bromoform standard calibration curve. Representative calculation: peak area 46,655,308 for California sample corresponds to $294.405 \mu \mathrm{M}$ of bromoform. When adjusted for dilution, peak area is equivalent to $46.5 \mu \mathrm{g}$ of bromoform in $1 \mathrm{mg}$ of dry biomass (4.65\% dry weight). 
A

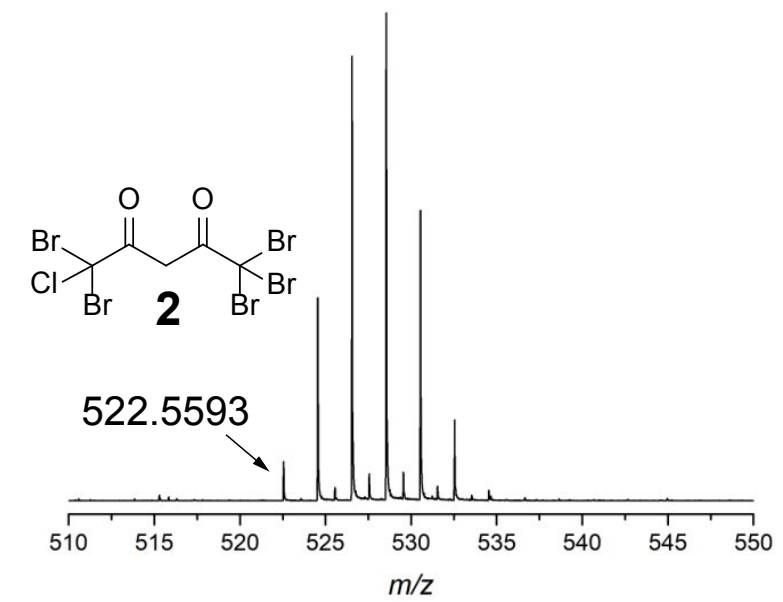

C
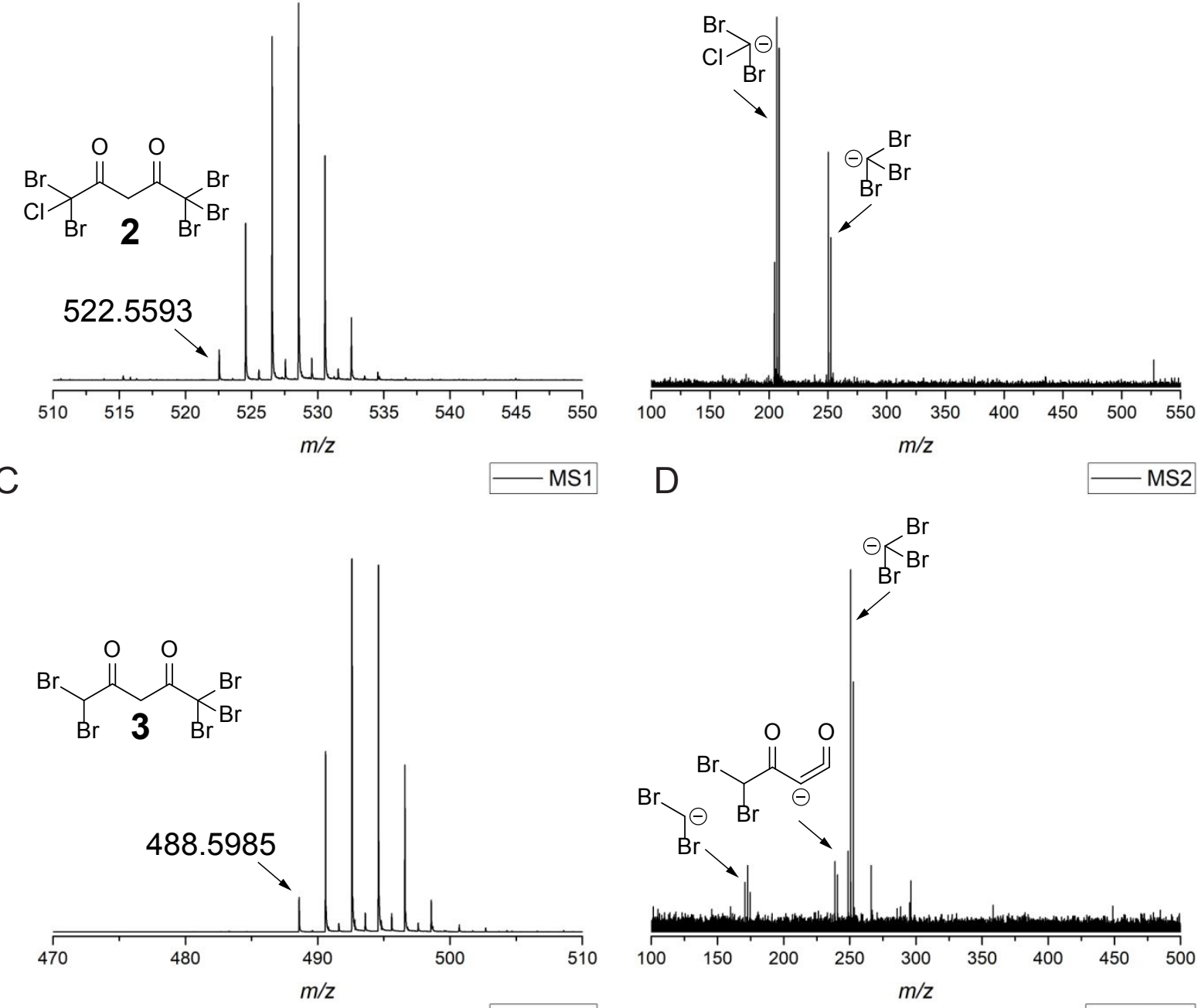

D

MS2

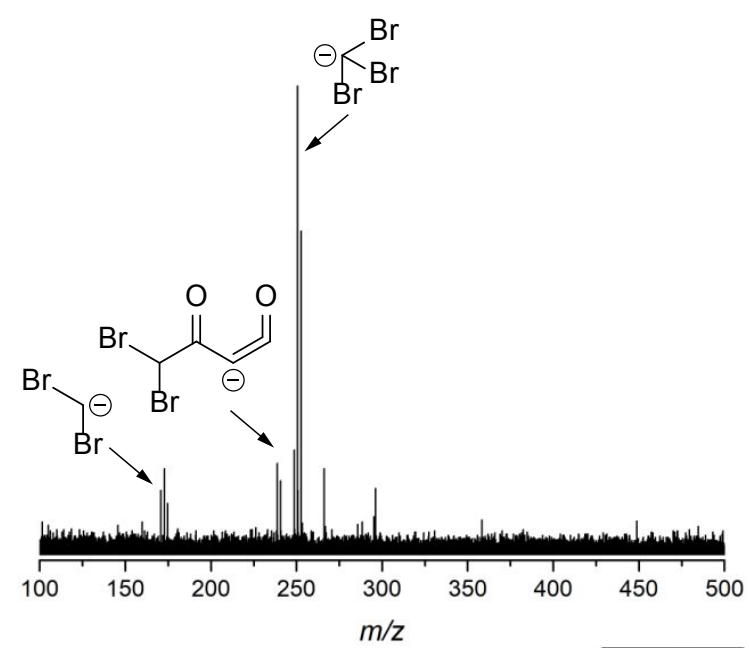

E
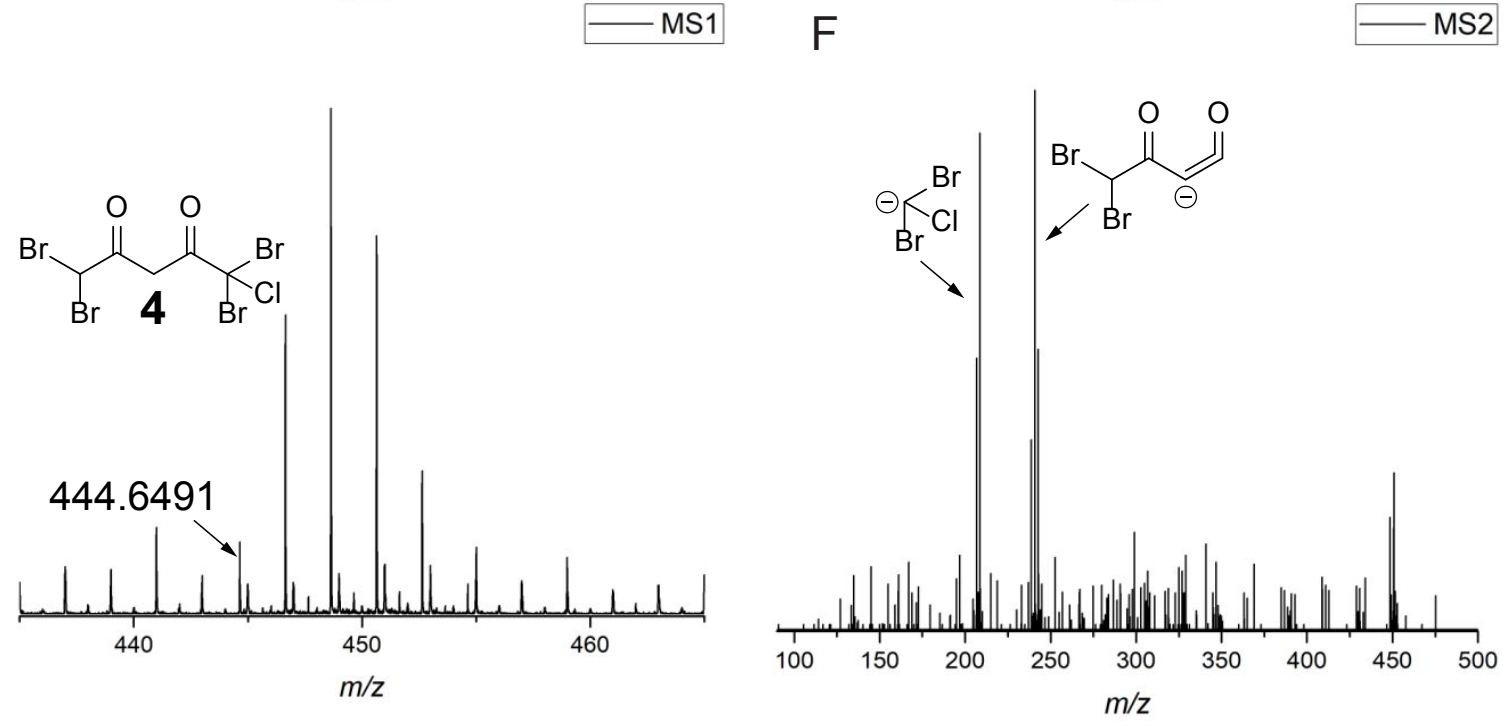

Figure S3: $\mathrm{MS}^{1}$ and $\mathrm{MS}^{2}$ spectra for 2-4. 
A
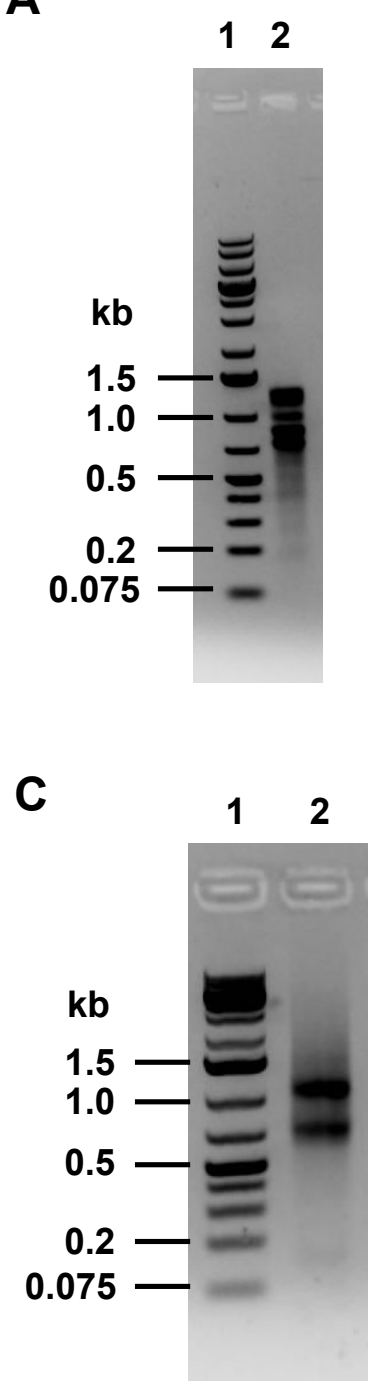

B
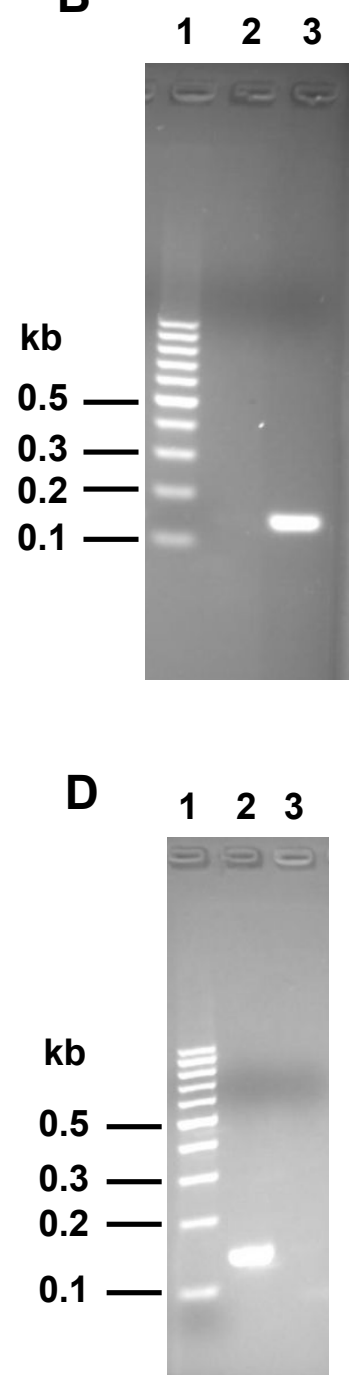

Figure S4: Total RNA and RT-PCR analysis by gel electrophoresis. Agarose gel pictures showing total RNA isolated from A. taxiformis collected from Guam (panel $\mathbf{A}$, lane 2) and California (panel $\mathbf{C}$, lane 2). RT-PCR reaction was done to amplify RuBisCo large subunit gene fragment using isolated RNA samples. Panel B; RT-PCR with Guam RNA in absence (lane 2) or presence (lane 3) of RT enzyme. Panel D; RTPCR with California RNA in presence (lane 2) or absence (lane 3) of RT enzyme. Lane 1 in each panel corresponds to DNA ladder. 


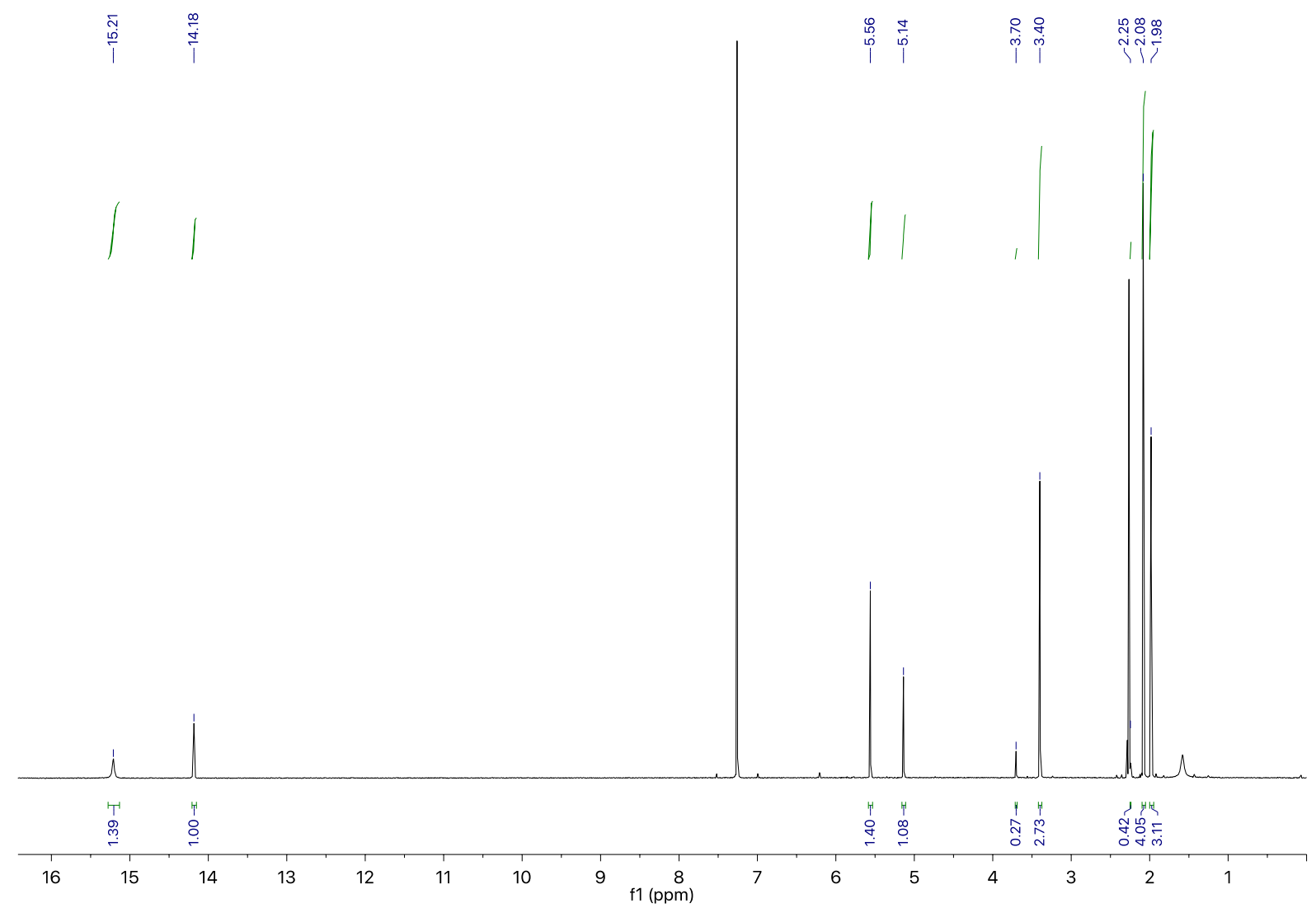

Figure S5: ${ }^{1} \mathrm{H}-\mathrm{NMR}\left(400 \mathrm{MHz}, \mathrm{CDCl}_{3}\right)$ spectrum for 6. 


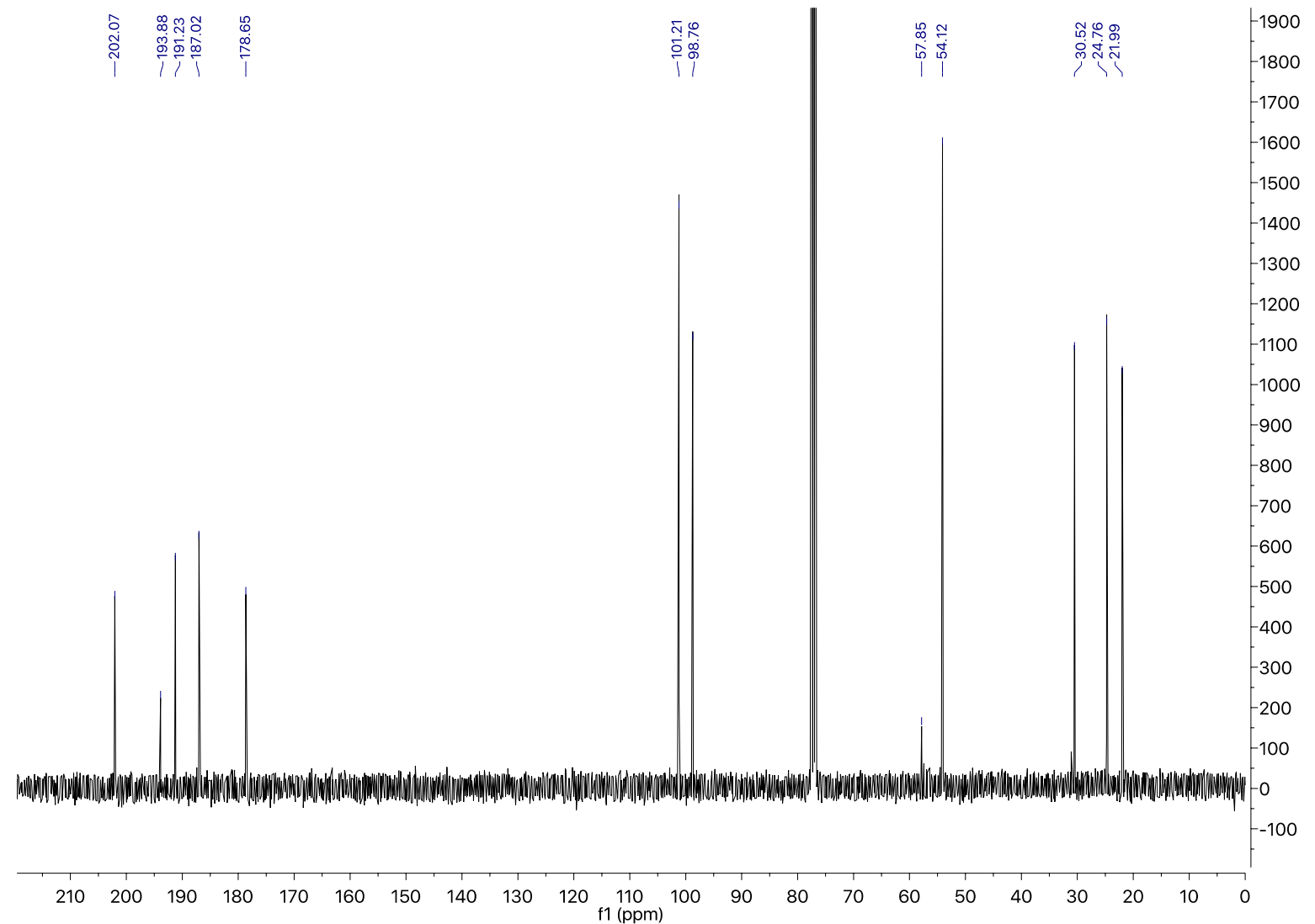

Figure S6: ${ }^{13} \mathrm{C}-\mathrm{NMR}\left(101 \mathrm{MHz}, \mathrm{CDCl}_{3}\right)$ spectrum for $\mathbf{6}$. 
CovBro

AtMbb1

AtMbb3

AtMbo 4

CCVHPO1

$\mathrm{CCVHPO} 2$

$\mathrm{CCVHPO} 3$

CovBro

AtMblo1

AtMbb3

AtMbb 4

CCVHPO1

CCVHPO2

CCVHPO 3

CovBPo

AtMbb1

AtMbb3

AtMbo 4

CCVHPO1

CCVHPO2

CCVHPO 3

CovBro

AtMbb1

AtMbo3

AtMbo 4

CCVHPO1

$\mathrm{CCVHPO} 2$

$\mathrm{CCVHPO} 3$

CovBPo

AtMbol

AtMbo3

AtMbb 4

CCVHPO1

CCVHPO2

CCVHPO3

AYLNACLILLANGVPFDPNLPFQ-----------QEDKLDNQDVFVNFGSAHVLSLVT AYLNACI ILLDIGAPFDSGIPFQ------------LDNDI DKQQGFATFGGPH I LSLVT AYLNACI ILLDINAPYDSGLPFT-----------ADDAVDKQQGFATFGAPHVLTLVT AYLNACI ILLDIKAPFDPHIPFQ-----------ADDDVDKQQGFATFGGPH I LSLCT AYLNACLIMLDSGVRFDKGIPFGE------------PDFKDHQRGFAHFGGPHILSLVT AYLNACI IMLNKKI PFDKGLPFQ-----------KDDDI DKQQGFALFGPPHILTLCT AYLNACLILLDNKVKFDQGIPMGEPDFNGNQGI PFQDPDFKDHQRGFAHFGGPHILSLVT

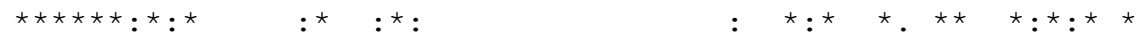

EVATRALKAVRYQKFNIHRRLRPEATGGLISVNKNAFLK---SESVFPEVDVLVEELSSEVATRALKAVRFQKFNVHRRLRPEAIGARVDRYCAT-KA-----PEFAGAAKLSEALDKE EVATRALKAVRFQKYAVHRRLRPEAVGGLLEQYRRYGGGHSDLAYI IRP IRHLADSLSSD EVATRALKAVRFQKYNLHRRLRPEAIGGLVERFKKTNGD-----PKFAPVKKLVNDLDGD EVATRALKAVRFQKFNTHRRLRPEAVGGLIERFNSNPDD-----PQFQDVKPLFEALDED EVATRALKGIRFQKYNVHRRLRPEAVGGRVERYHHNCED-----PLFADVKPLYDALDKD EVATRALKAVRFQKFNTHRRLRPEAVGGLIERFNSNPDD-----PQFQDVKPLFEALDED

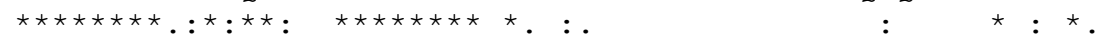

ILDDSASSNEKQNIAD--------GDV-----SPGKSFLLPMAFAEGSPFHPSYGSGHAV LLQKVHDHNKKQNLL-SDRGNPRANDFNPDGEVSEGNLLMPMAFPEGSPMHPAYGAGHAT LMSMVAKENGRQNSLIRDNGHPRSHDE-----GSDDTHLLSMAYAEGSPMHPSYGAGHAT MLRRVEQHNCEQNKL-SDDGHARREDYSPEGESSQ-SYLLPMAFPEGSPMHPSYGAGHAT MMRRVARHNREQNQG-SDFGMPRADDFNPAGDTLE-TMLLPMAFPEGSPMHPSYGAGHAT MLERVAAHNAEQNAK-DDFGNSRFEDYSPTGSSGR-TYLLPMAFPEGSPMHPAYGAGHAA MLRRVASHNREQNER-SDFGMPRADDFNPAGDTLE-TMLLPMAFPEGSPMHPSYGAGHAT

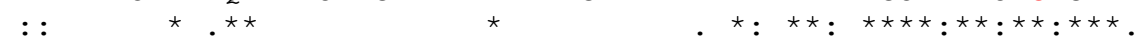

VAGACVTILKAFFDANFQI DQVFEVDTDEDKLVKS--SFPGPLTVAGELNKLADNVAIGR VAGACVTVLKAFFDGGYRLPFCYITDEDGTGLQAV--EIDEPLTVDGELNKICSNISIGR VAGACVTILKAFFDHTFKLPFAYVSSSDGRKLKTV--KLSKKLTVEDELNKLAANIS IGR VAGACVTVLKAFFDHEYELDFCYVPTTDGKRLEKV--NINEKLTVEGELNKLCANIS IGR VAGACVTVLKAFFQHDTELDFCFVPSDDGSRLVDASHNMNKKLTVEGELNKVCSNIS IGR VAGACTTILKAFFDHEHELDFAYVPTADGSKLEDVVDS LGEKLTVEGELNKVCSNISVGR VAGACVTVLKAFFQHDATLDFCYVPSDDGSRLDDASHTLNKKLTVEGELNKVCSNISIGR

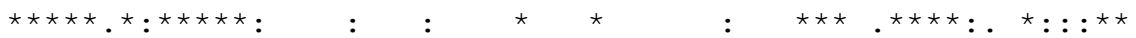

NMAGVHYFSDQFESLLLGEQIAIGILEEQSLTYGENFFFNLPKFDGTTIQI-----NWAGVHYFTDYIESIRIGEEIAIGILQEQKLTFSENFSMTLNKFDGSTIRI-----SWAGVHYYSDYVES IRLGEEVAI GMLKEQKLTYSEKFTMTI PKEDGSVIEI-----NWAGVHYYSDYFES IKVGEEIAIGILQEQKLTYGEDFFMTLPKFDGEKIRI-----NWAGVHYFTDYIES I LLGEQIALGILEEQMLTFPETFTMTVPLFSGELKVLRST--NWAGVHYFTDYRES I ILGEKIALGLLEEQKLTYAEEFSMTI PLFDGSTVTI-----NWAGVHYFTDYIES ILLGEQIALGILEEQMLTFPETFTMTVPLFSGGFRTLISTSDP

Figure S7: Amino acid sequence alignment of VHPO and Mbb proteins from marine red macroalgal species. Only partial amino acid sequences for each protein is shown and alignment was generate using Clustal Omega. ${ }^{21}$ All vanadate binding residues except for Ser483 in CoVBPO is strictly conserved between $A t \mathrm{Mbb}$ and $C c \mathrm{VHPO}$ proteins. Accession numbers and percent identity of proteins with $C o$ VBPO are shown in parenthesis: Corallina officinalis CoVBPO (PDB 1QHB_A; 100\%), AtMbb1 (50.44\%), AtMbb3 (47.53\%), AtMbb4 (52.24\%), C. crispus CcVHPO1 (Genbank XP_005714237.1, 50.53\%), CcVHPO2 (GenBank XP_005719435.1, 47.83\%), and CcVHPO3 (GenBank XP_005710894.1, 50.26\%). 
A
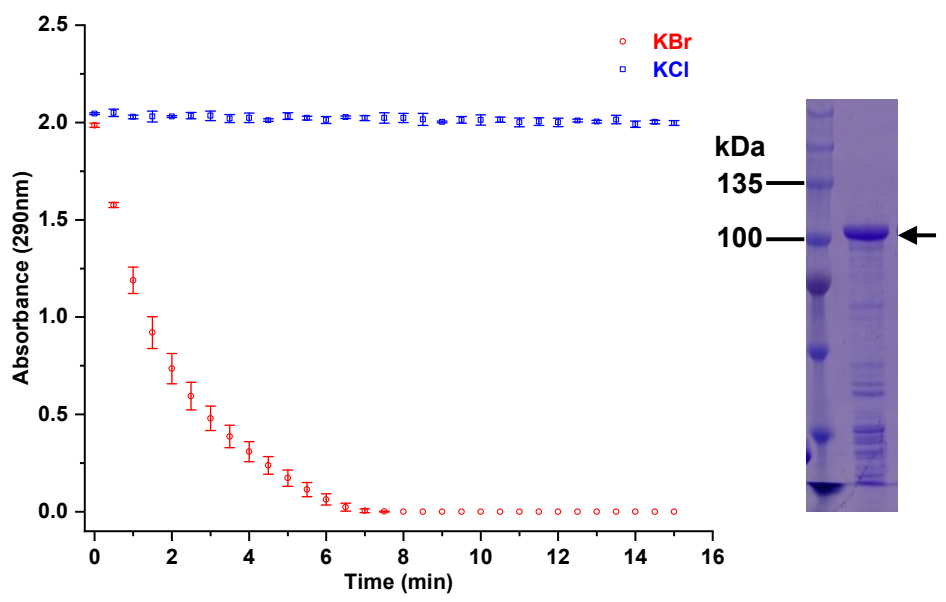

B

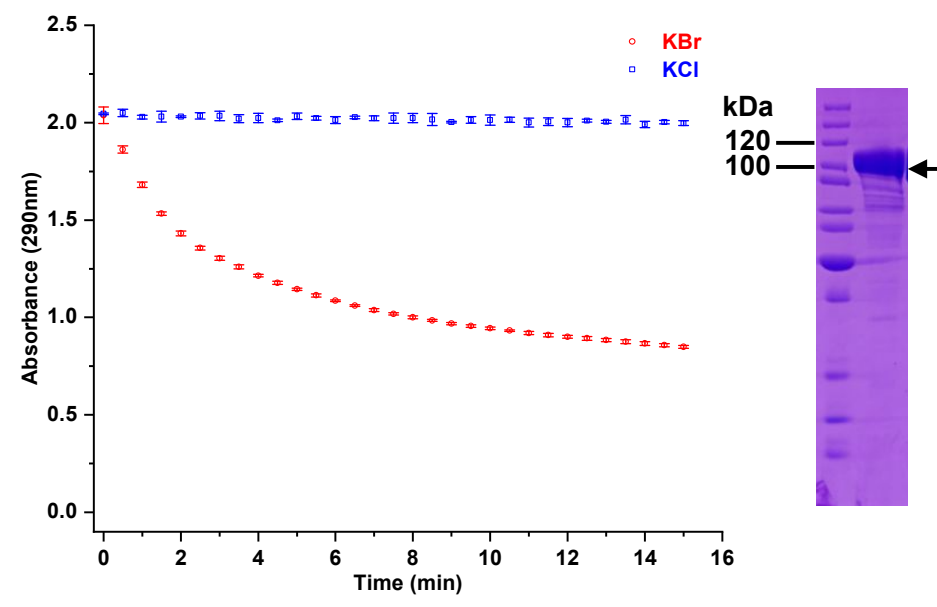

C

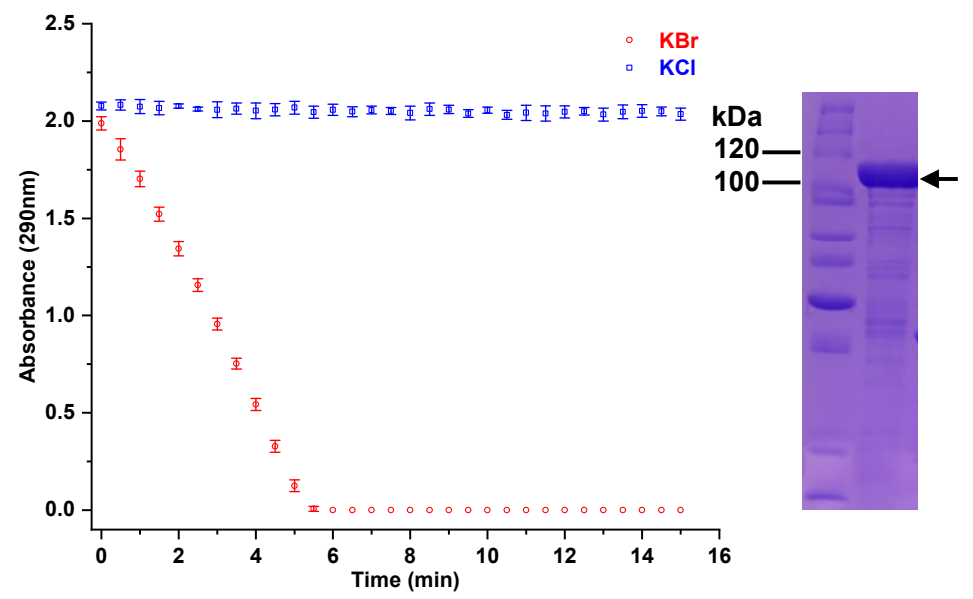

Figure S8: Monochlorodimedone (MCD) assay with recombinant Mbb VHPOs using $\mathrm{KBr}$ and $\mathrm{KCl}$ as halide sources. Change in absorbance of MCD substrate at $290 \mathrm{~nm}$ over the time when incubated with $\mathrm{Mbb}$ enzymes in a MCD assay: (A) Mbb1 (250 nM), (B) Mbb3 (1 $\mu \mathrm{M})$, and (C) Mbb4 (100 nM). Concentration for each enzyme used here was empirically determined due to difference in the activity of individual enzymes. SDS-PAGE gel on right panel of each graph demonstrates the purity of Mbb proteins: His-MBPMbb1 (110.6 kDa), His-MBP-Mbb3 $(110.9 \mathrm{kDa})$ and His-MBP-Mbb4 (111.8 kDa). 


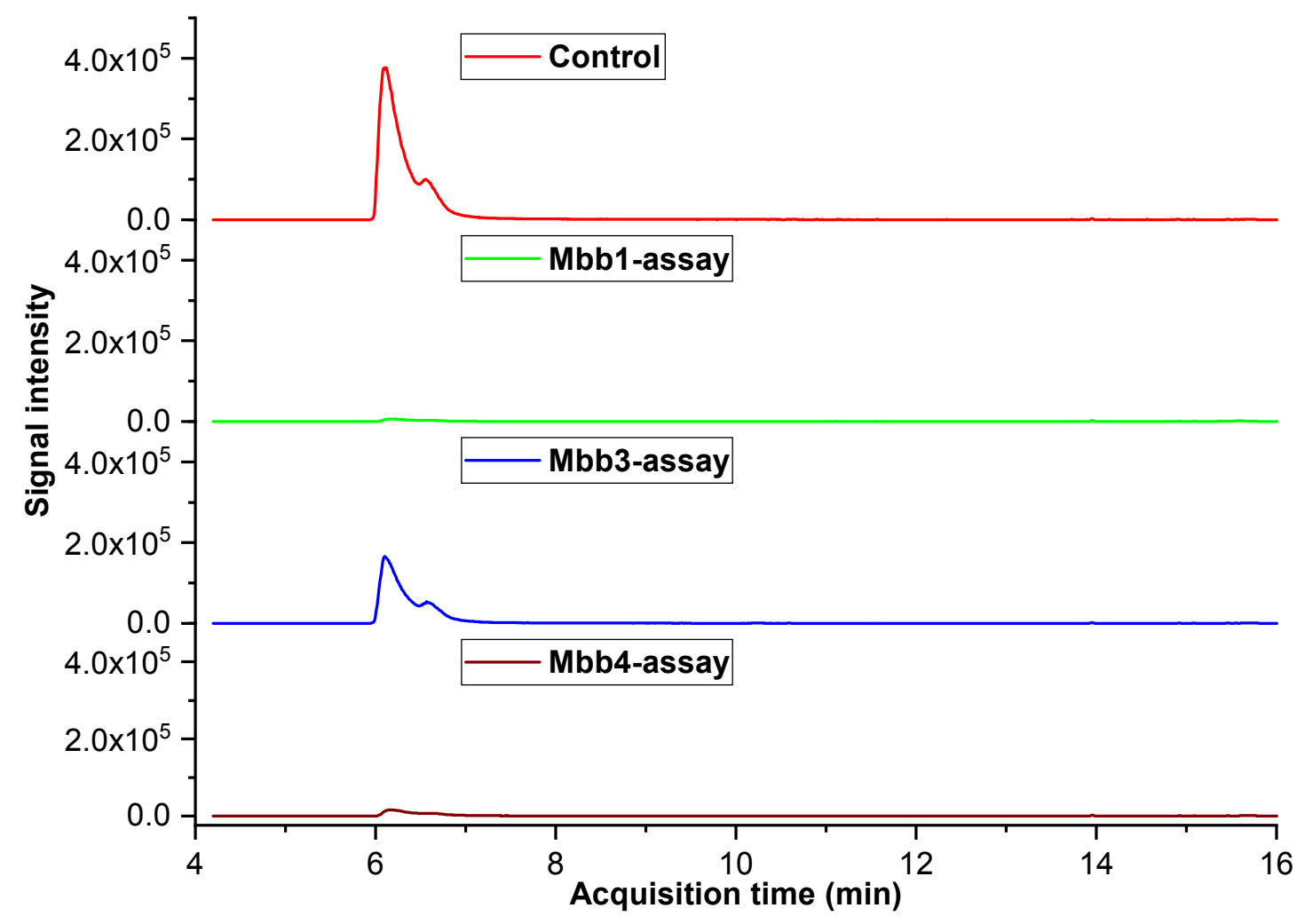

Figure S9: GC-MS analysis of enzyme assay products showing turnover of substrate 5. Assays were conducted with recombinant Mbb VHPOs. Extracted ion chromatograms for molecular ion $\mathrm{m} / \mathrm{z} 100.05$ for 5. 


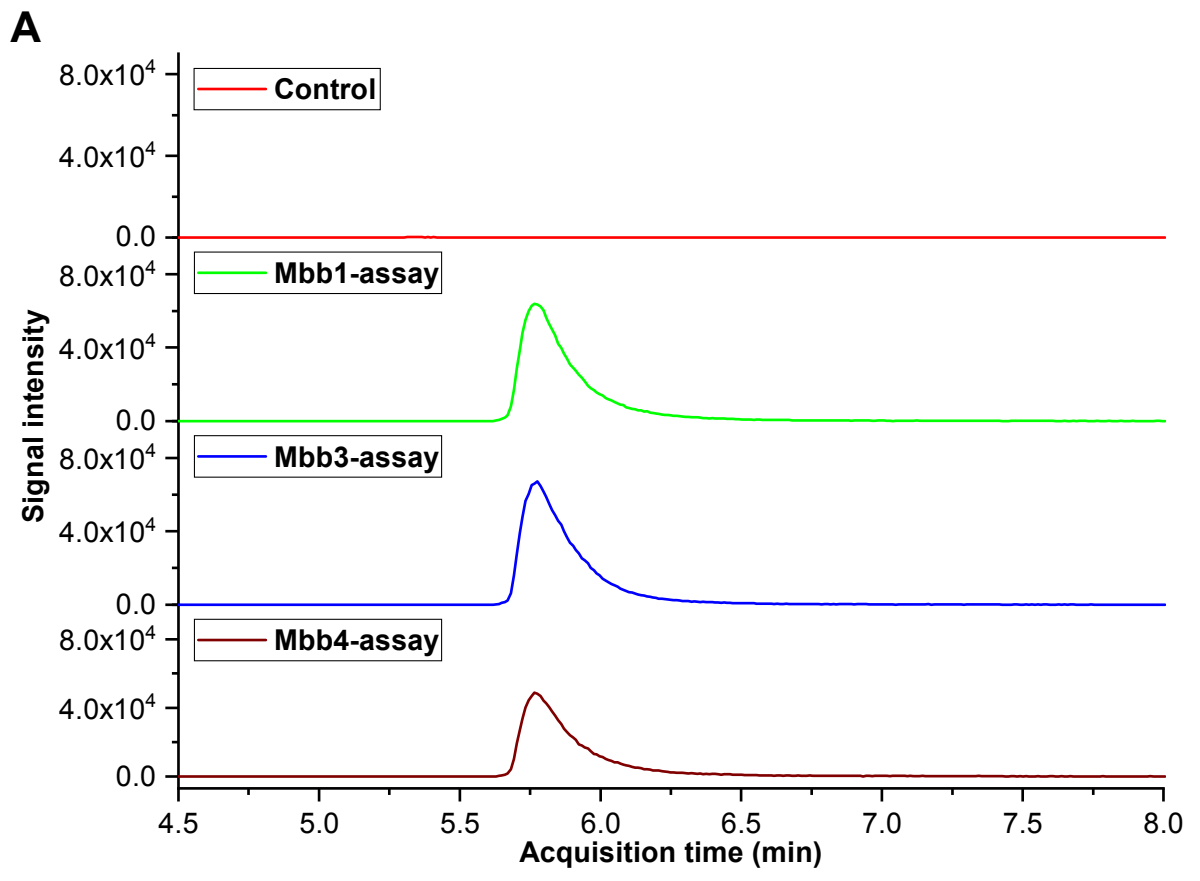

B

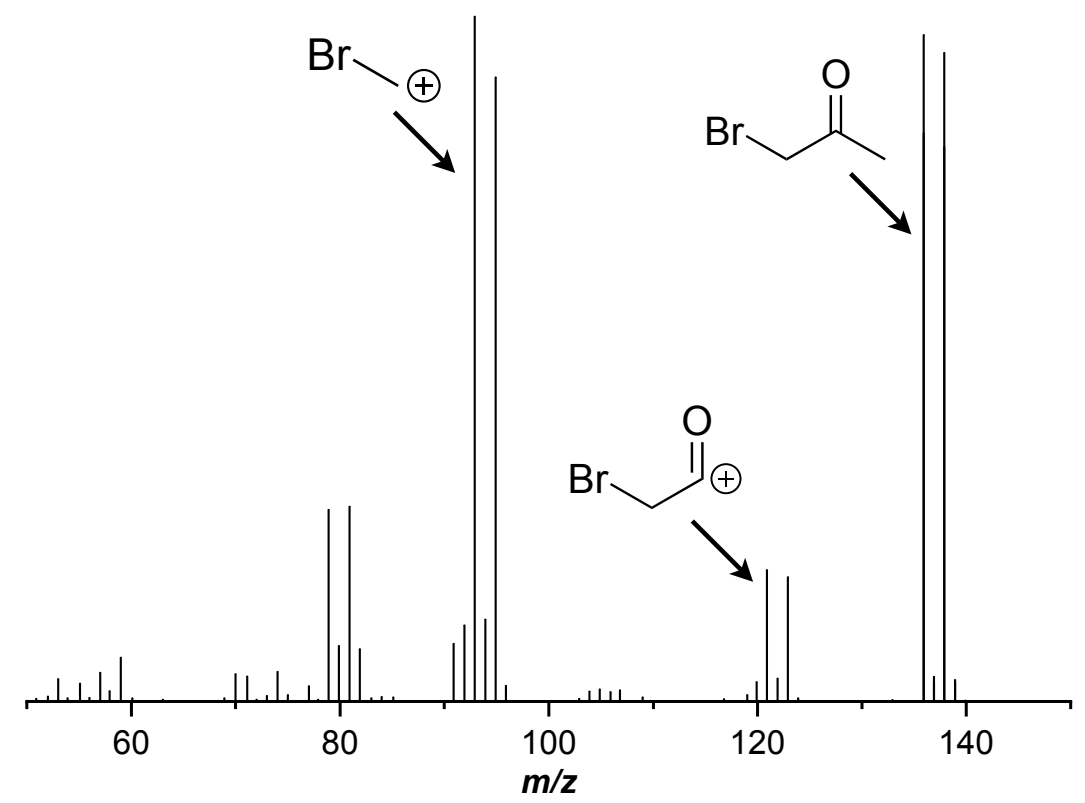

Figure S10: GC-MS analysis of enzyme assay products. Assays were conducted with recombinant Mbb VHPOs using 5 as substrate. (A) Extracted ion chromatograms for most abundant isotopic ion $\mathrm{m} / \mathrm{z} 135.95$ for monobromoacetone. (B) MS spectrum supports the structural assignment for monobromoacetone by annotation of fragment ions. Arrow corresponds to monoisotopic ion of each molecule. 
A

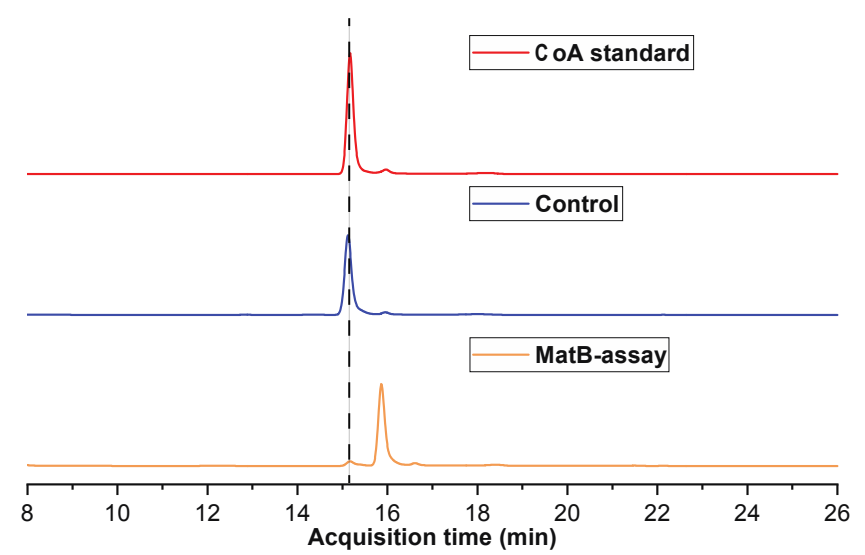

B
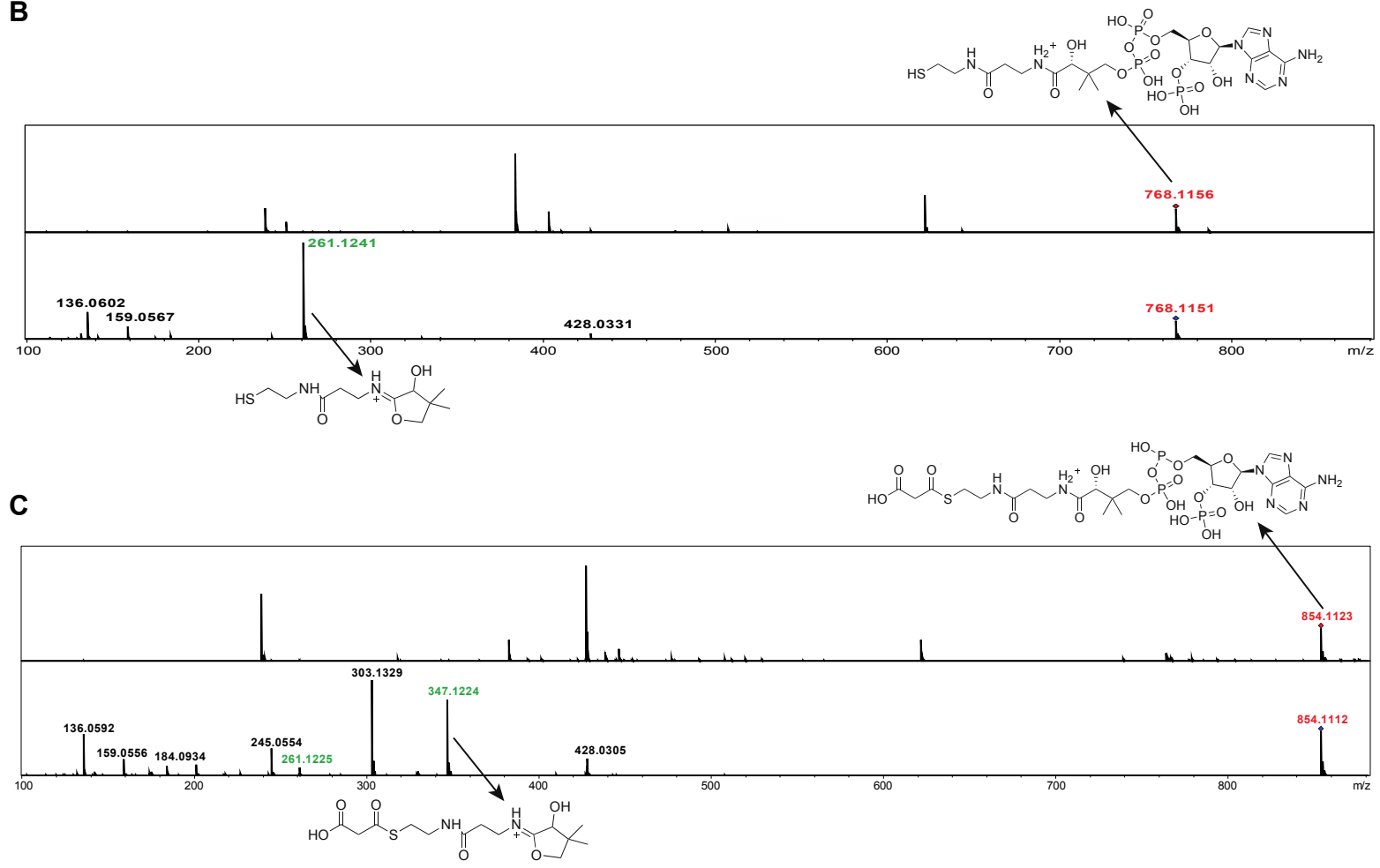

Figure S11: Enzymatic synthesis of malonyl-CoA. (A) HPLC chromatogram showing synthesis of malonyl-CoA when CoA-SH and malonic acid were used as substrates in an $\mathrm{ATP} / \mathrm{Mg}^{+2}$ dependent assay with MatB enzyme. ${ }^{11}$ Control reaction was done in the absence of MatB. (B) $\mathrm{MS}^{1}$ (top) and $\mathrm{MS}^{2}$ (bottom panel) spectra for CoA-SH. The characteristic (cyclo)pantetheine $\mathrm{MS}^{2}$ product ion is observed in the $\mathrm{MS}^{2}$ spectra. $^{22}$ (C) $\mathrm{MS}^{1}$ (top) and $\mathrm{MS}^{2}$ (bottom panel) spectra for malonyl-CoA. The characteristic malonyl-S(cyclo)pantetheine $\mathrm{MS}^{2}$ product ion is observed in the $\mathrm{MS}^{2}$ spectra. 

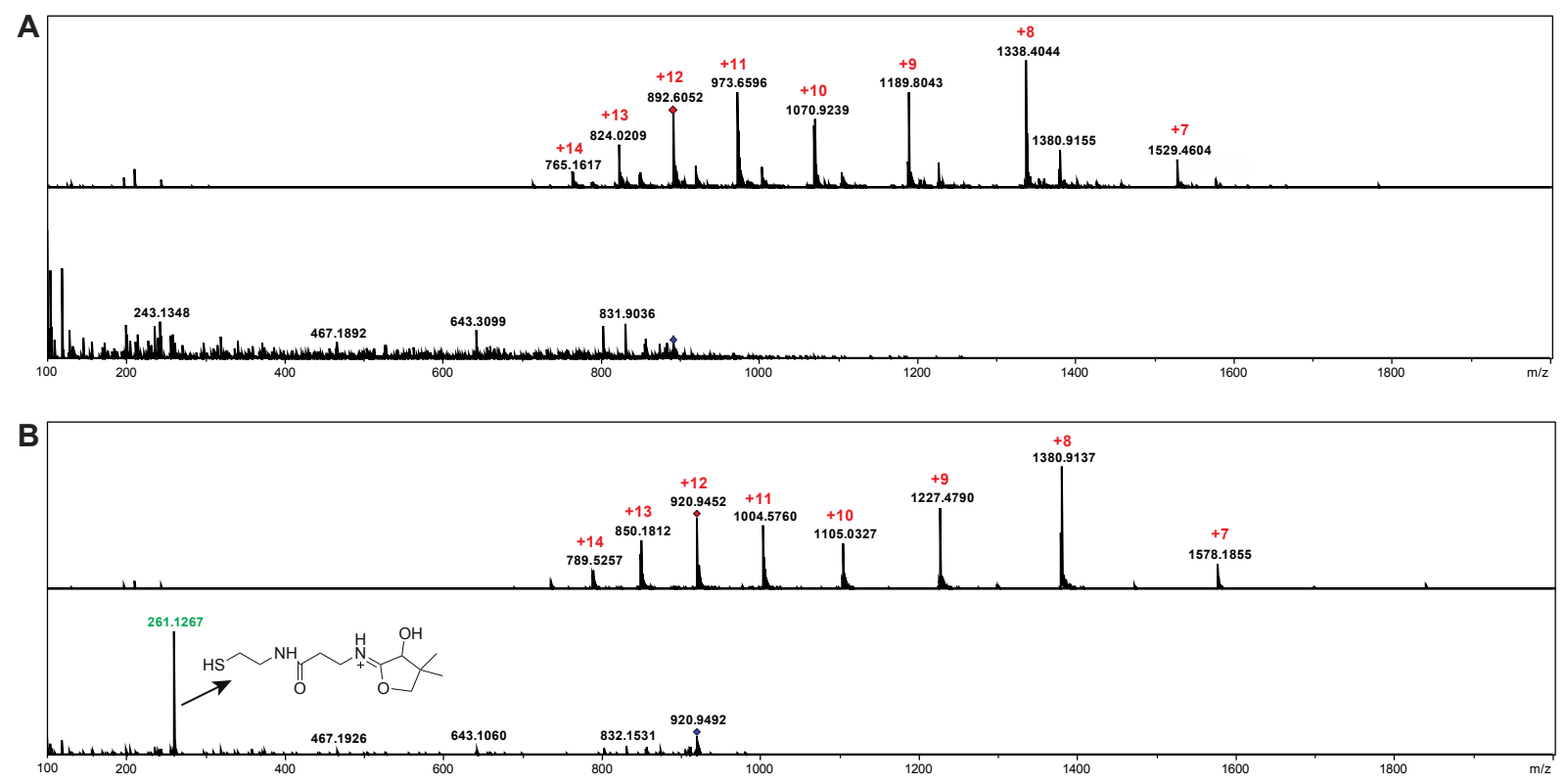

Figure S12: Mass spectrometric characterization of apo-ACP and holo-ACP. (A) MS ${ }^{1}$ (top) and MS ${ }^{2}$ (bottom panel) spectra corresponding to apo-ACP. Multiple charge states are observed in $\mathrm{MS}^{1}$ spectrum. The (cyclo)pantetheine ejection ion is not observed for apo-ACP in the $\mathrm{MS}^{2}$ spectrum. (B) $\mathrm{MS}^{1}$ (top) and $\mathrm{MS}^{2}$ (bottom panel) spectra corresponding to holo-ACP. Multiple charge states of peptides are observed in $\mathrm{MS}^{1}$ spectrum and MS ${ }^{2}$ spectrum of holo-ACP shows a characteristic (cyclo)pantetheine ejection ion at $\mathrm{m} / \mathrm{z}$ 261.12 . 

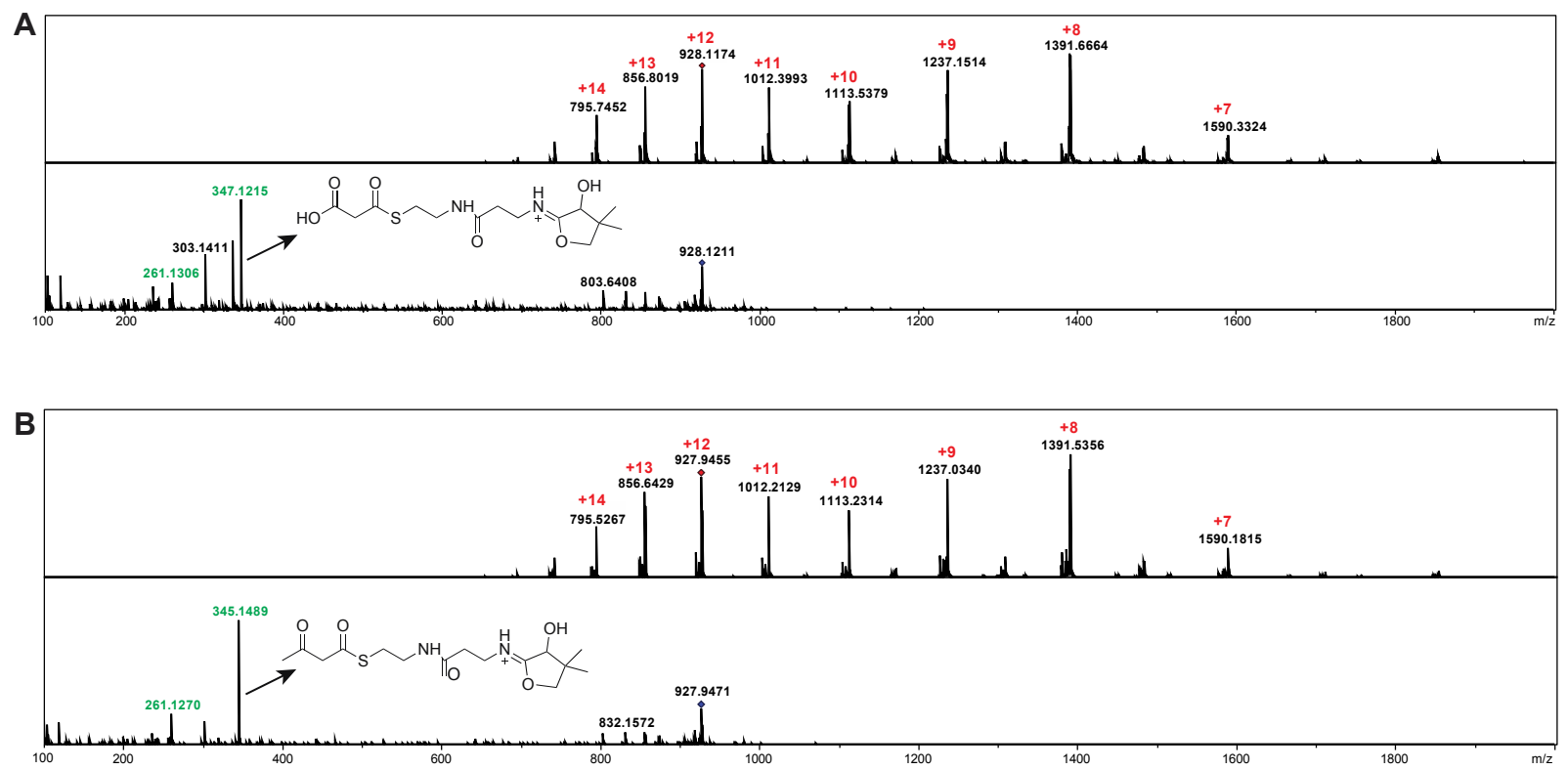

Figure S13: Mass spectrometric characterization of malonyl-S-ACP and acetoacetyl-S-ACP (8). (A) $\mathrm{MS}^{1}$ (top) and $\mathrm{MS}^{2}$ (bottom panel) spectra corresponding to malonyl-S-ACP. Multiple charge states of peptides are observed in $\mathrm{MS}^{1}$ spectrum and $\mathrm{MS}^{2}$ spectrum of malonyl-S-ACP shows a characteristic malonyl-S-(cyclo)pantetheine ejection ion at $\mathrm{m} / z$ 347.12. (B) $\mathrm{MS}^{1}$ (top) and $\mathrm{MS}^{2}$ (bottom panel) spectra corresponding to acetoacetyl-S-ACP. Multiple charge states of peptides are observed in $\mathrm{MS}^{1}$ spectrum and $\mathrm{MS}^{2}$ spectrum of acetoacetyl-S-ACP shows a characteristic acetoacetyl-S-(cyclo)pantetheine ejection ion at $m / z 345.14$. 
A. taxiformis Mbb2

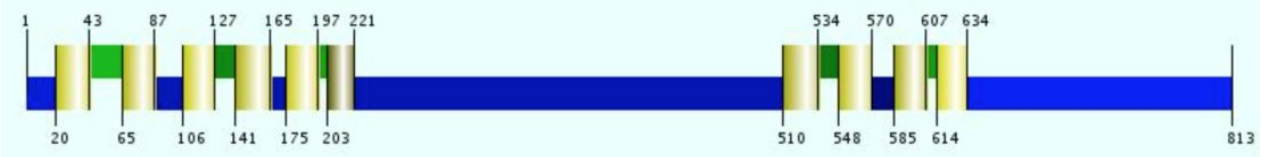

C. crispus NOX

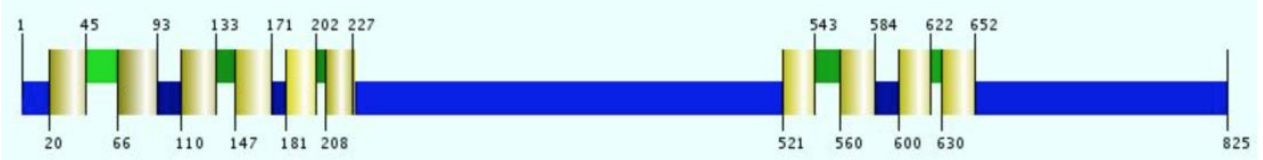

C. stagnale NOX5

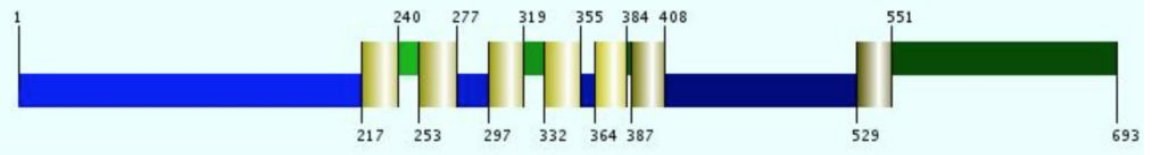

H. sapiens NOX5b

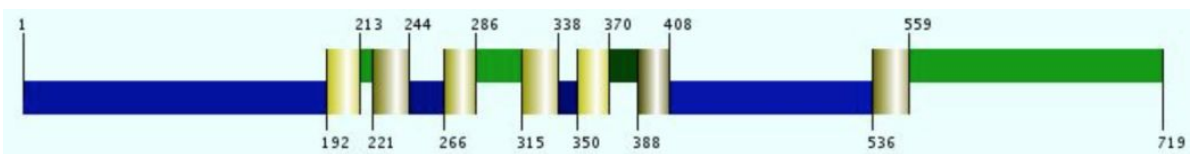

S. cerevisae YNO1
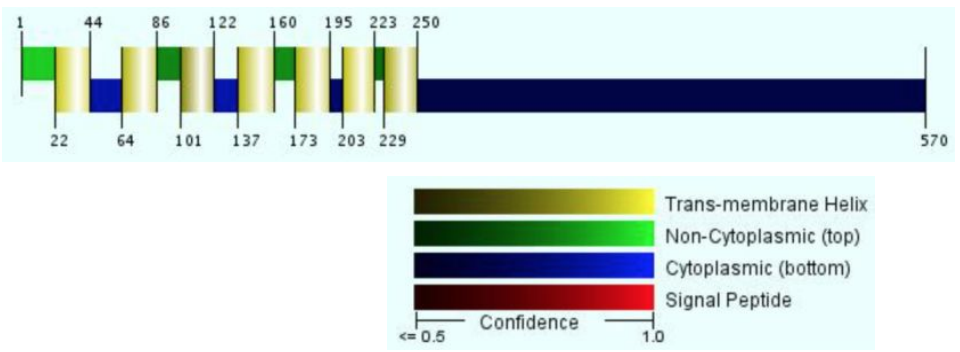

Figure S14: Transmembrane domain prediction for NOX protein sequences using the Phillius transmembrane prediction server. ${ }^{23}$ Genbank accession numbers and percent identity of proteins with Mbb2 is shown in parenthesis: Red macroalga Asparagopsis taxiformis Mbb2 (100\%), red macroalga Chondrus crispus NOX (Genbank XP_005719187; 48.81\%), cyanobacterium Cylindrospermum stagnale (Genbank WP_015206836; 27.27\%), human NOX5b (Genbank AAK57193; 30.51\%), and yeast Saccharomyces cerevisiae YNO1 (Genbank NP_011355; 15.78 \%). Human NOX5b is used for comparison as it showed highest identity to Mbb2 when compared to all seven human NOX proteins. ${ }^{24}$ Cyanobacterial NOX5 is used for comparison as its crystal structure has been elucidated. ${ }^{25}$ Although yeast YNO1 showed low identity to $\mathrm{Mbb} 2$ when compared to other NOX proteins, it is shown here to highlight the difference in organization of transmembrane domains between NOX protein sequences. Furthermore, yeast with deletion of ynol gene is used for in vivo characterization of Atmbb2 and CcNOX genes. 
AtMbb2

CCNOX

CSNOX5

HsNOX5b

AtMbb2

CCNOX

CsNOX5

HSNOX5b

AtMbb2

$C \mathrm{NOX}$

CSNOX 5

HsNOX5b

AtMbb2

CCNOX

CSNOX5

HSNOX5b

AtMbb2

CCNOX

CSNOX5

HsNOX5b

AtMbb2

CCNOX

CSNOX5

HSNOX5b

AtMbb2

CCNOX

CsNOX5

HSNOX5b

AtMbb2

CCNOX

CsNOX5

HSNOX5b

AtMbb2

CCNOX

CSNOX5

HSNOX5b

AtMbb2

CCNOX

CSNOX5

HSNOX5b

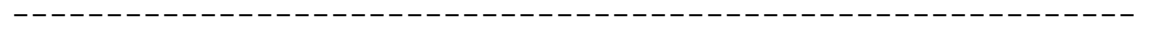

MGLLTVLSLKYHNEFLTRTEINIIVDTPKKTLEELRRVFTQIAKEDKQIDQAEFKSALGL ----------------MSAEEDARWLRWVTQQFKT IAGEDGE I S LEFKAALHV 60 38

-

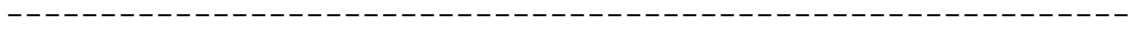
KDEYFVDRLFSIFDTDSSGTIKIEEFLTTVENLVFATSEEKLQFAYELHDVNGDGCIEKA KESFFAERFFALFDSDRSGTITLQELQEALTLLIHGS PMDKLKFLFQVYDIDGSGS I DPD

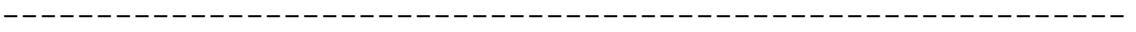

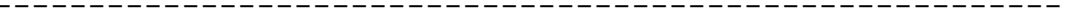
EISHLITASLKENNLSFSPEQINELVDLLFREADADKSGEISFAEFKGLIEKFPDLIEAM ELRTVLQSCLRESAISLPDEKLDQLTLALFESADADGNGA ITFEELRDELQRFPGVMENL

0

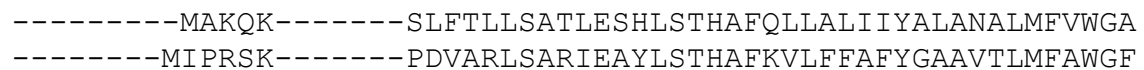
TVSPISWLKPHKQDSIAVLPKERMDSQKAY IKYYIENNWVKIAFLALYVFVNMFFFMSAV TISAAHWLTAPAPRPRPRR-------PRQLTRAYWHNHRSQLFCLATYAGLHVLLFGLAA

$$
\text { . : : : : : } \quad \text { * : : }{ }^{\star} \text {. }
$$

HDEFHHHT-----NANNLRWY ICIARGAGYTLNLNTALVILLAARLFATYLRETPLQHIL KAEFTFEDNF DMP HFNTVRWF I GIARGMGYTLNLNTAFVILLASRLLFTKLRDS PLQLVL EKY---------ESQGANLYVQIARGCGATLNLNGAL I L I PMLRHFMTWLRKTTINNYI SA-----------HRDLGASVMVAKGCGQCLNFDCSFIAVLMLRRCLTWLRATWLAQVL 259

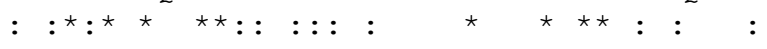

PLDKSFPAFH IVVAYTIAAAVVIHASFHLAWLVAYDM--------W-------ETGMWGF 144 PFDAAFPALHIVVGYTIFFAVLVHGSFHFVWLITWDA--------W-------TWGLWSF 150 PIDESI-EFHKLVGQVMFALAIVHTGAHFLNYTTL------PIPFAQSLFGTK------- 336 PLDQNI-QFHQLMGYVVVGLSLVHTVAHTVNFVLQAQAEAS PFQFWELLLTTRPGIGWVH 318 ${ }^{\star}:{ }^{*}: \quad:{ }^{*}:: . \quad .: \quad::^{\star}$

TMSAATGVVLLVVF IVMFISAMPKYRK-KHFRIFYLIHSVGALLFFGLLVFHGMYNRVPE NMSVITGFLLAIVF GTMLVLARPSVRK-NNFRLFYAVHI I GATLFFGLLI IHGMFRQVPY --AGISGFLLLLVF I IMWVTAQAP IRKGGKFALFYIAH-MGYVLWFALALIHG--- - PV GSASPTGVALLLLLLLMF ICSSSCIRRSGHFEVFYWTH-LSYLLVWLLLIFHG-----PN

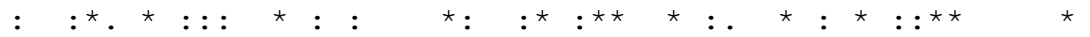

TYKWIAAPLI IYT I DRVLRRYKISTAELELTGEHSS LKGSDILELRVPKPFDYQAGQYAE TYKWVI PP L I LYA I DRFLRRRKVSAVELFLSAENAVLKDGD I LELRVPKAFSYQAGQYAE FWQWVLLPVVGF I IELVIRWKTTKE-PTFVVNAS LLPSKVLGLQVQRPQSFNYQPGDYLF FWKWLLVPG I LFFLEKA I GLAVSRMAAVC IMEVNLLPSKVTHLL I KRP PFFHYRPGDYLY

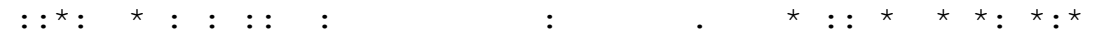

VCVKSIN-SEWHPETIASSPHE-DSMCFYIKALGDWTTNLRDAFEARVE---------- 310 $\begin{array}{ll}\text { VQVPFIN-REWHPFTIASAPQD-KTMCFYIKALGDWTKELRGAFQARVD---------- } & 316 \\ \text { IKCPGISKFEWHPFTISSAPEMPDVLTLHIRAVGSWTGKLYQLIREQREEWI------- } & 499\end{array}$ LNIPTIARYEWHPFTISSAPEQKDTIWLHIRSQGQWTNRLYESFKASDPLGRGSKRLSRS 492

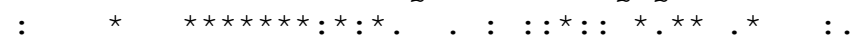




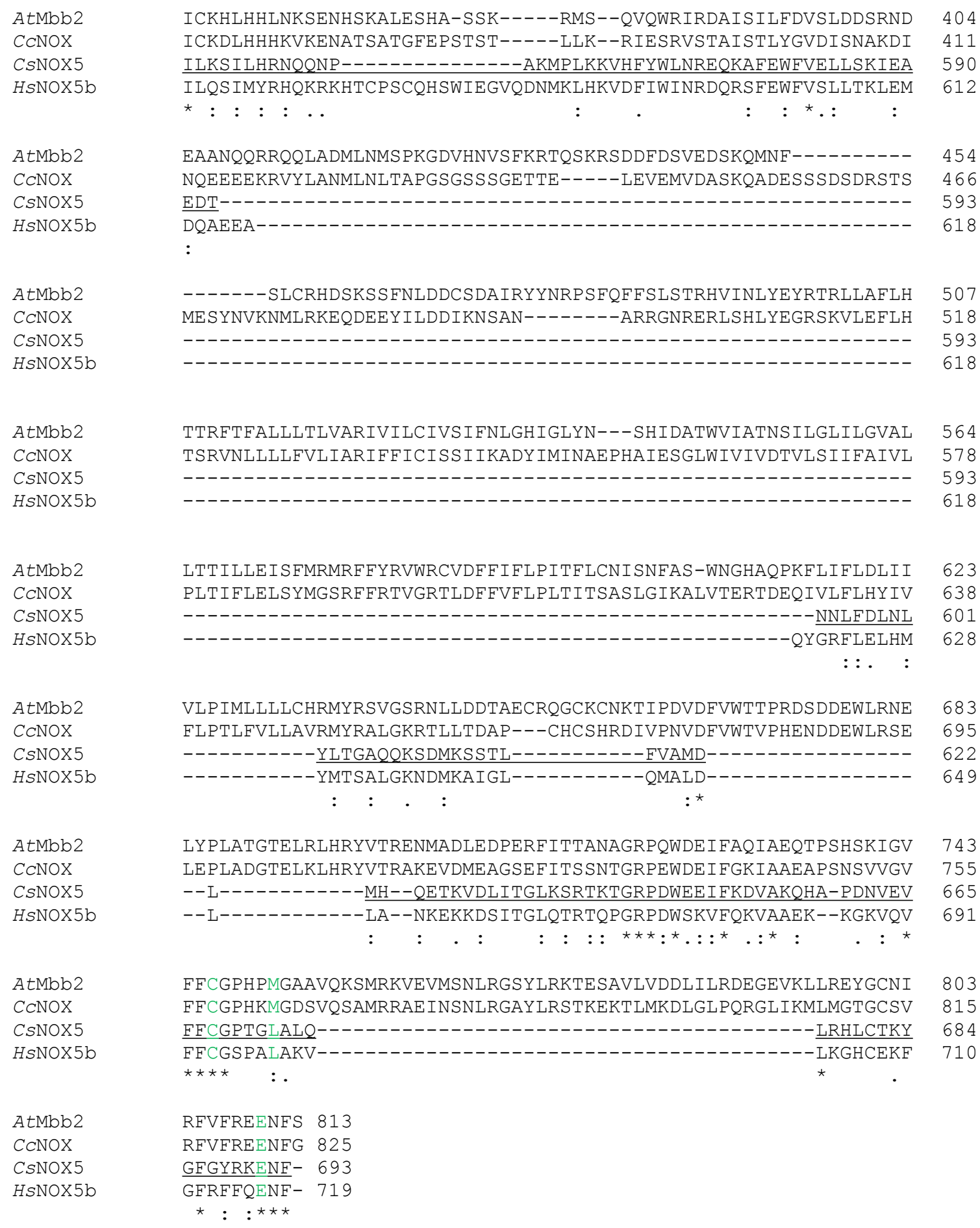

Figure S15: Amino acid sequence alignment of NOX protein sequences using Clustal Omega. ${ }^{21}$ Four NOX protein sequences, Cylindrospermum stagnale NOX (CsNOX), Asparagopsis taxiformis NOX (AtMbb2), Chondrus crispus NOX ( $C c \mathrm{NOX})$ and Human NOX5b, were used for alignment. Yeast NOX was excluded in alignment study due to its low amino acid identity to other NOX proteins. Residues numbers described 
here correspond to $C s \mathrm{NOX}$ protein and their structure to function relationship is inferred from study describing the crystal structures of transmembrane domain and dehydrogenase domain of CsNOX protein. ${ }^{25}$ Four histidine residues (His313 and His385 ligated to phorphyrin of extracytoplasmic heme, highlighted in green, and His299 and His372 ligated to phorphyrin of cytoplasmic heme, highlighted in red) involved in heme binding in $C s \mathrm{NOX} 5$ protein are conserved in $A t \mathrm{Mbb} 2, C c \mathrm{NOX}$ and $H s \mathrm{NOX} 5 \mathrm{~b}$ proteins. The two His residues mutated to Ala (data for loss of NOX activity shown in Figure 4B) are highlighted in bold. Similarly, other hydrophobic residues (Met306, Phe348 and Trp378) that intercalates between two heme groups and dioxygen substrate binding residues (His317 and Arg256) in CsNOX5 are also conserved among other NOX proteins, and are highlighted in magenta letters. Residues corresponding to dehydrogenase domain of $C s \mathrm{NOX}$ is underlined. The NADPH and FAD binding residues are highlighted in green and purple letters, respectively. 
A

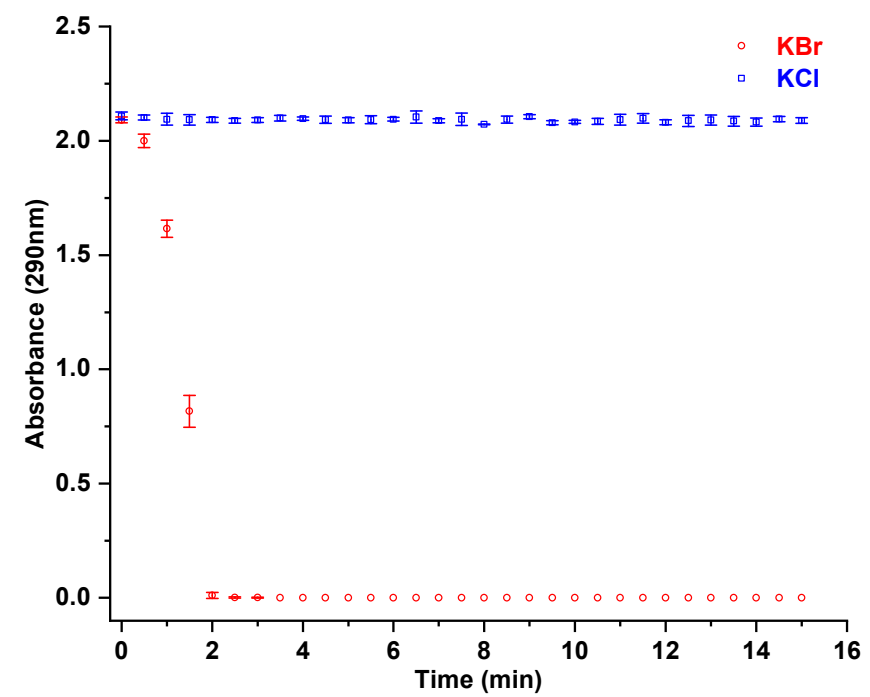

B

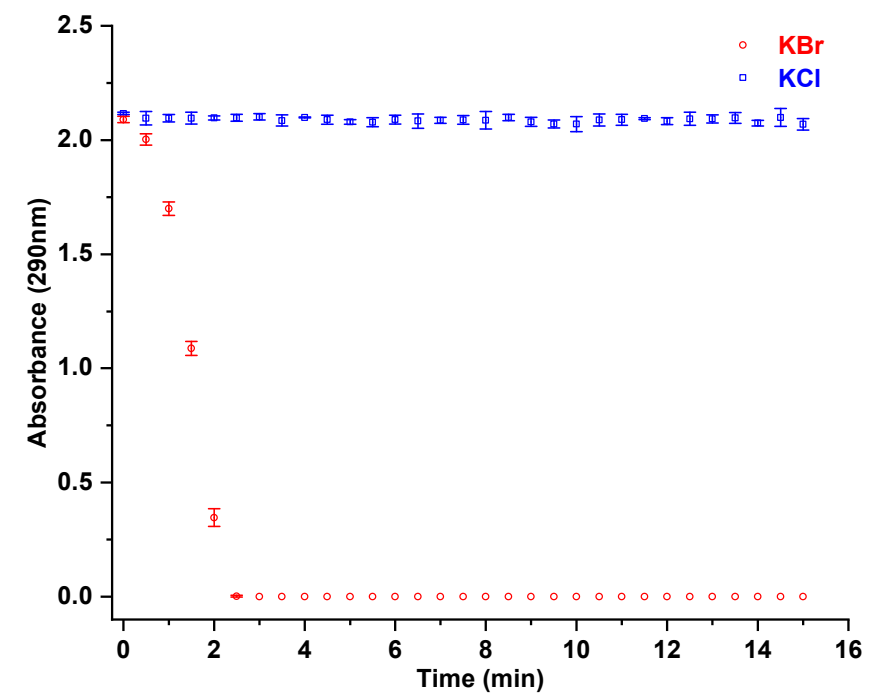

C

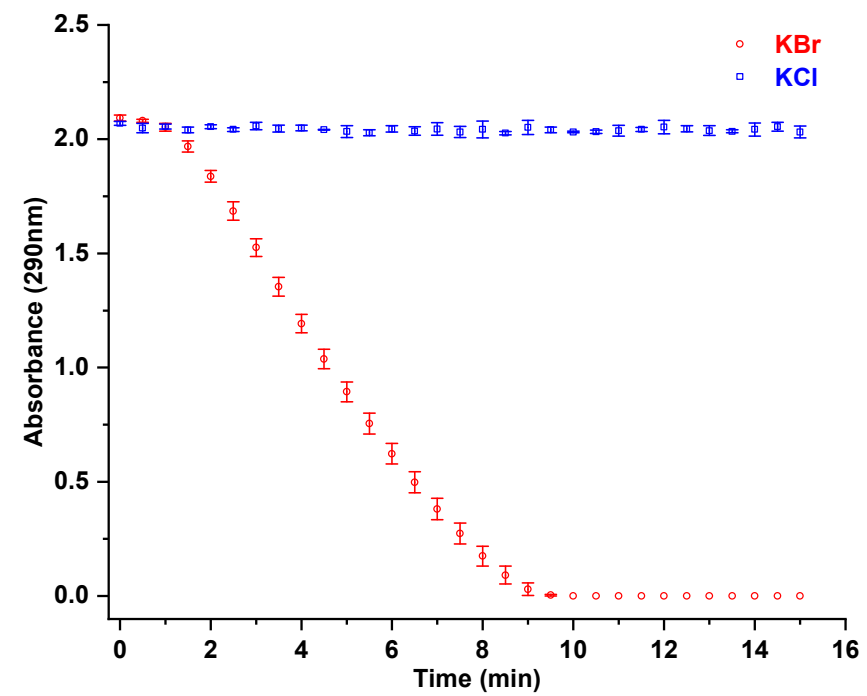

Figure S16: Monochlorodimedone (MCD) assays with recombinant CcVHPOs. Change in absorbance of MCD at $290 \mathrm{~nm}$ was recorded over the time in assays with (A) CcVHPO1 (50 nM), (B) CcVHPO2 (50 nM), and (C) CcVHPO3 (250 nM). Two different halide sources, $\mathrm{KBr}$ and $\mathrm{KCl}$, were tested in separate assays, and the enzyme concentrations used here were empirically determined. 

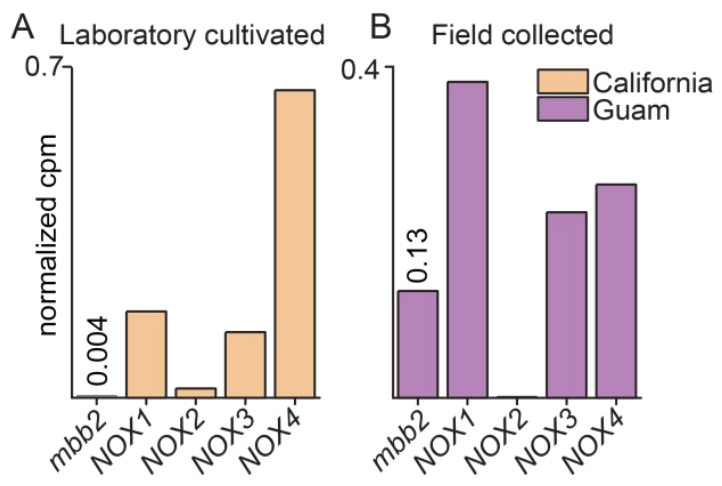

Figure S17. Individually normalized counts per million (cpm) transcript levels for NOX encoding genes in (A) laboratory cultivated (California) and (B) field collected (Guam) A. taxiformis samples. 

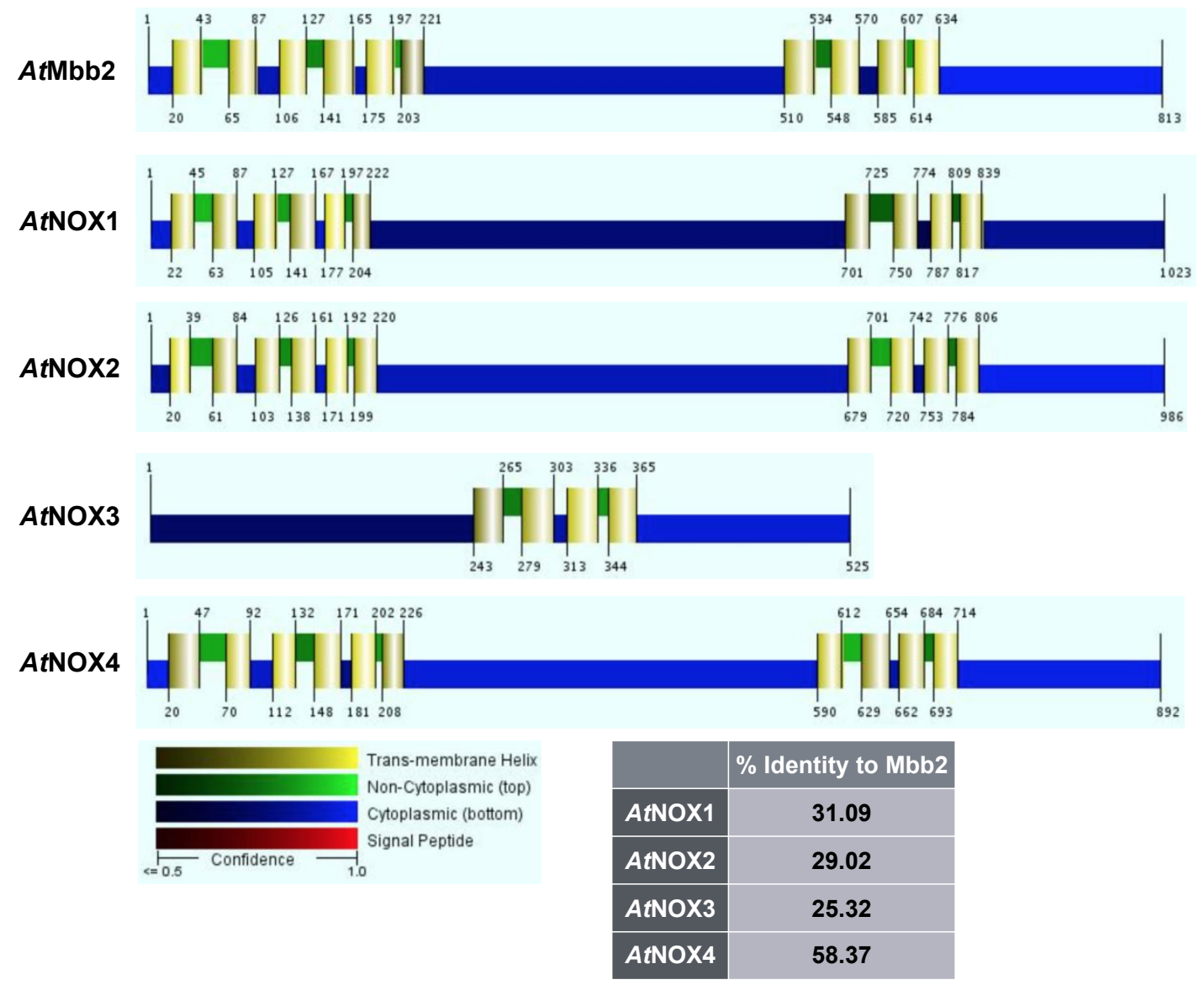

Figure S18: Transmembrane domain prediction for Asparagopsis taxiformis NOX-like protein sequences using the Phillius transmembrane prediction server. ${ }^{23}$ Percent identity of $A t \mathrm{NOX}$ proteins to $A t \mathrm{Mbb} 2$ is shown in table, and was determined based on protein sequence alignment generated using Clustal Omega. ${ }^{21}$ GenBank accession numbers is shown in parenthesis: AtNOX1 (GenBank MN911452), AtNOX2 (GenBank MN911451), AtMbb2 (GenBank MN893468), AtNOX3 (GenBank MN911453) and AtNOX4 (GenBank MN911454). 


\section{SUPPLEMENTARY TABLES}

Supplementary Table S1. Shortgun sequencing and assembly results.

\begin{tabular}{|c|c|c|c|c|c|c|c|c|c|}
\hline & $\begin{array}{l}\text { trimmed } \\
\text { reads } \\
\text { (pair) }\end{array}$ & contig \# & $\begin{array}{l}\text { n50 } \\
\text { (bp) }\end{array}$ & $\begin{array}{l}\text { longest } \\
\text { contig } \\
\text { (bp) }\end{array}$ & $\begin{array}{l}\text { Total } \\
\text { assembly size } \\
\text { (bp) }\end{array}$ & $\begin{array}{l}\text { Sequencing } \\
\text { method }\end{array}$ & $\begin{array}{l}\text { Library } \\
\text { size }\end{array}$ & GC\% & $\begin{array}{l}\text { Read } \\
\text { length } \\
\text { (bp) }\end{array}$ \\
\hline $\begin{array}{l}\text { California } \\
\text { gDNA }\end{array}$ & $85,676,804$ & 1104938 & 2261 & 2019246 & $1,517,284,223$ & $\begin{array}{l}\text { Illumina } \\
\text { NovaSeq }\end{array}$ & $\sim 450$ & 51 & 151 \\
\hline $\begin{array}{l}\text { Guam } \\
\text { gDNA }\end{array}$ & $105,547,008$ & 980759 & 773 & 744171 & $765,833,334$ & $\begin{array}{l}\text { Illumina } \\
\text { NovaSeq }\end{array}$ & $\sim 450$ & 46 & 151 \\
\hline $\begin{array}{l}\text { California } \\
\text { mRNA }\end{array}$ & $44,450,663$ & 20789 & 3018 & 20984 & $35,660,953$ & $\begin{array}{l}\text { Illumina } \\
\text { NovaSeq }\end{array}$ & $\sim 450$ & 50 & 151 \\
\hline $\begin{array}{l}\text { Guam } \\
\text { mRNA }\end{array}$ & $98,748,611$ & 151422 & 783 & 38841 & $113,504,178$ & $\begin{array}{l}\text { Illumina } \\
\text { HiSeq } 2000\end{array}$ & $\sim 350$ & 47 & 125 \\
\hline
\end{tabular}


Supplementary Table 2: Amino acid and nucleotide sequence identity between Mbb proteins and $m b b$ genes from Guam and California samples. Genes $m b b 1, m b b 3$ and $m b b 4$ encodes for VHPO proteins.

\begin{tabular}{|l|c|c|}
\hline & Amino acid similarity (\%) & Nucleotide similarity (\%) \\
\hline Mbb1 & 96.949 & 96.221 \\
\hline Mbb2 & 98.770 & 97.052 \\
\hline Mbb3 & 96.558 & 95.246 \\
\hline Mbb4 & 96.587 & 95.060 \\
\hline
\end{tabular}


Supplementary Table 3: List of $E$. coli expression constructs used in this study.

\begin{tabular}{|c|c|c|c|c|}
\hline Gene & Plasmid & Fusion tag & Source organism & Reference \\
\hline$m b b 1$ & pET-28MBP 26 & $\begin{array}{l}\text { N-terminal 6xHis- } \\
\text { MBP }\end{array}$ & A. taxiformis (Guam) & This study \\
\hline$m b b 3$ & pET-28MBP & $\begin{array}{l}\text { N-terminal 6xHis- } \\
\text { MBP }\end{array}$ & A. taxiformis (Guam) & This study \\
\hline$m b b 4$ & pET-28MBP & $\begin{array}{l}\text { N-terminal 6xHis- } \\
\text { MBP }\end{array}$ & A. taxiformis (Guam) & This study \\
\hline$a c p$ & pET-28b & N-terminal 6xHis & A. taxiformis (Guam) & This study \\
\hline$f a b H$ & $\mathrm{pET}-28 \mathrm{~b}$ & N-terminal 6xHis & A. taxiformis (Guam) & This study \\
\hline CCVBPOI & pET-28MBP & $\begin{array}{l}\text { N-terminal 6xHis- } \\
\text { MBP }\end{array}$ & C. crispus & This study \\
\hline $\mathrm{CcVBPO2}$ & pET-28MBP & $\begin{array}{l}\text { N-terminal 6xHis- } \\
\text { MBP }\end{array}$ & C. crispus & This study \\
\hline CCVBPO3 & pET-28MBP & $\begin{array}{l}\text { N-terminal 6xHis- } \\
\text { MBP }\end{array}$ & C. crispus & This study \\
\hline matB 11 & pET-28MBP 26 & $\begin{array}{l}\text { N-terminal 6xHis- } \\
\text { MBP }\end{array}$ & Streptomyces coelicolor & This study \\
\hline$s f p$ & pET-24b & C-terminal $6 \mathrm{xHis}$ & Bacillus subtilis & $\begin{array}{l}\text { Agarwal et al. } \\
(2014)^{27} \text {; Quadri } \\
\text { et al. }(1998)^{13}\end{array}$ \\
\hline
\end{tabular}


Supplementary Table 4: List of primers used for qRT-PCR

\begin{tabular}{|l|l|l|l|}
\hline Gene & Sample & qPCR-forward primer & qPCR-reverse primer \\
\hline$a c t i n$ & Guam & GCATGACCCAGATCATGTTCGAG & CATAGATAGGGACGGTATGGGTGAC \\
\hline$m b b 1$ & Guam & GAAGTTGGCGATGGATTCATCCAG & CTTCTTTGTACAATTCGCGACCGG \\
\hline$m b b 2$ & Guam & GTGAGTGGCATCCGTTTACAATTG & CTTGAGCGGTTCGTACAGATCATTC \\
\hline$m b b 3$ & Guam & GTCCAACAGATGCTGTTTGCCTC & GTGTACATCGGCGAGACCCTTG \\
\hline$m b b 4$ & Guam & GAGATTACGGAGAGCTATTGGATGGC & CTTCATCGGTCAATGTTGACGGAC \\
\hline$a c t i n$ & California & GCATGACCCAGATCATGTTCGAG & CATAGATAGGGACGGTATGGGTGAC \\
\hline$m b b 1$ & California & GCAGAGTCCATCAATAACACCCAATG & CGACAAGGAGGAACTGTGACAGATAG \\
\hline$m b b 2$ & California & GTGAGTGGCATCCGTTTACAATTG & GTGGTTCGTACAGATCATTCTCAACTCG \\
\hline$m b b 3$ & California & CTGTGCACGACATGAATCATACCC & CTTTGTGCCGACAAGGAGAAACTG \\
\hline$m b b 4$ & California & GAGATTACGGAGAGCTATTGGATGGC & CTTCATCGGTCAATGTTGACGGAC \\
\hline
\end{tabular}

All primers are listed from 5' to 3'. 
Supplementary Table 5: List of heme-peroxidase genes and their corresponding transcript level (counts per million) in California and Guam transcriptomes. Amino acid sequences for each hemeperoxidase gene is listed below.

\begin{tabular}{|l|l|l|}
\hline & California cpm & Guam cpm \\
\hline heme-peroxidase1 & $19,036,838$ & $96,857,763$ \\
\hline heme-peroxidase 2 & $22,132,794$ & $716,554,924$ \\
\hline heme-peroxidase3 & $31,815,891$ & $43,638,708$ \\
\hline heme-peroxidase4 & 296,421 & $162,957,571$ \\
\hline heme-peroxidase5 & $430,173,245$ & $57,252,885$ \\
\hline
\end{tabular}

$>$ Heme-peroxidase 1

MS L I IHLLILSLLVVRHPAAAFPLCPARRTFS GACSSLFNPSWGAINTPHRRLIASPIPLPSDLPSPRLISNILCRHNDVKSTRYL NELTTFFGQFVDHNIVLTPADGPLFPI PVPPSDPLFANFSNGLPFHRSRRVQAFTDHVFSERGP PDVFVP INVVSSVLDLSAVYGP TISRVRALRGNGGKLKTSHNGRFLPFNHPHLDNEPTTGNIFFVAGDTRSNEHPVLTALHTLFVREHNDLVDELASKFSNYSDDWLF QTARAINIAQFQKITLEHFYPAMTGRGLPPSS LFS DKYVDAS I I DVFATAAFRVGHTMVNDVISPRDKHGPLAS I KMSETFFQPGE HMVHTDI DRFLRGAAWVRAQQVDLAVVDALRNHLFT SVRGEEGVDLVAMNIQRSRDNGLPSYNDIREAVGI PRASCFANISRKVSV QTALSTAYGSVDRVEAWI GMVAEDHAPGAAMGETLIAVWELQFRKIRDGDRLYFRKPGLFPDVVTDQ IARVRDLFYDSDTLRNIVL RNTDIEDDELPRRMFFV

$>$ Heme-peroxidase2

MISATILSLLLAASLTAALPSPAVHQDALTRVNCEISARFFDGTCTNPSNPAYGQATEAVFSYIPNLSSATFSSRGRPDARLISNA VCDQDSPVFNDRNLNELLVFFGQFLDHDLVLSEAGDETVPIPVPADDPNTDVSS LPFRRNIRVSVPGEAPGTVRPENLLSQI I DLS MVYGSDSGRANALRTFEEGRLKVSSDNLLPLNTEGLSNEPSTSENFFVAGDIRSNETPMLTVLHTIWVREHNNI IDELVQSRTENR LSDDGLYELARRINIAQFQKVVWEEFFPAIVGRS LPRYRGFNPNVNPTVSNIFATAAFRVGHTMVGDGVQVVQGSTRTVLPVTEMF FREQSFFRSTGLDSFLLGAVTTRCQE I DNKVVNVLRNGLFSS I PGVSGFDL ISLNIQRGRDHN I PSYNEVRELFGIERAQSFADIT SDTDVQARLASVYDDI DDVDAF I GLISEEHVSGGS LGVTMRAIWTTEFTRLRDGDQFFYLRNGLFSS PLRREIRRVRMLRGRRGIF RDIVLRNTGLTPSQVPRRPFFV

$>$ Heme-peroxidase 3

MTATPSNLLRPIFLVALLAAFATQAFSQAARGNGFGASVLQPIEPGVPEFRERKTDPCRDDYRTYDGSCNNKRMKLWGSAGLPHFS YLPLRLSTKPKGRNLKSARQ ISN I LSKQTTDIFNSRCLSEFFVFFGQFIDHTFAATPVENTKEFPIKI PADDPIFANFSGGVLPFE RSRRGRVAGGLADLP INSVTSFLDLSSVYGSDDIRIQKLRTYKNGRMRTTKGNLLPLNTDSLRNAPTNGPMFFAAGDHRANEHPML TS I HTLFVRE HNSLADELRAKF PQWDDERLFQTARKIAIAEFQNIVFEGFFPAMTGRKLWEYRGYKRNVNPTLSDEFVTAAFRVGH TMVGNEVKRA GPNNTPLSP I SMKKMFFQPHTVMSRGVEQFLRGA I I T PCQEVDVHVRNS LRDFLFTDIKEEKGFDLVALNLQRGRD HGLPTYNELRVRFGRP PAFRFSEITRKRNLQSALANAYGNPNKVEAWI GLMCEDH I KGAS IGKTLYRIWRREFRRMRAGDRFFYMV PGLFEKEVRDKIQRVQDLFTDKDIMKGILLRNTKLTSEEIGESVWKADRCLANSN

$>$ Heme-peroxidase 4

MKFNLKFSFLS I LALLSTSFALPTRLNTNVRQFNCQYQTRMLDGTCTNNIQPELGSTGRAVSSLLRNRSSKRPSSAKTTLPSARFI SNTVSKQDGD I LNDRGLNELVTFFGQF I DHTVVFTPVSETHMDI P I PEDDDIFANFTGGVLEFRRSERVPLAPGSRRERPVNELSA ALDLASVYGVDQERNEELRTLVDGKLKTSPGNLLPLNTAGLPNAPSTGPNFFLAGDERANENPTLSALHTLFVLEHNNICDELKTN FPSYTDEQLYETARKINIAEFQKITYEEFYPALTGRRIRRYRGFRATTDVGVLNEFATAGFRVGHTLVGNAIHRTGPGNSPRPDIP FGEMFFRSAEVLQDNGIDEFIRGATQFEAQEVDLKVHDALRNGLFQGI PGEDAGFDLIALNLQRSRDHNL ISYNQLRKRLGGGRAR NFAQ INRNVNI QNLLSTAYDGDVDKVEAWVGMMAERHERGGSFGPTLRKLWDKQFRMFRDGDRFFYLNDIFSTELRNAIPRIDALR ADSETFRDIIIRNTDITDSELPRRIFFTQ

>heme-peroxidase 5

MMSHIRSTALVAFVLLALSSFVVGMPP PQGRKYASRARI PTAQRQISCDIDTRSLDGQCTNPTDPSWSATDTAQFSYIEGHSSNIP TGENLPSPRL I SNTLCMQSEDLFNDRE ISEFFTFFGQLVDHDLYLTPTSEDEFPIPIGPEDEIFGMFPGDVLEFTRSERVPIVEGE IAERPVNTVSGALDLSTVYGSSEERNAALREENSCKLLVSEGDLLPLNTMQ I PNSPTTDPNMFVAGDTRSNEHPVLATMHTLFVRE HNY ICDQLAVLMPNTTAEEQYENART INIAEFQDVVYDEFFPALIGRTLAPYEGFDPSVDPTPSNVYGAAGFRIGHTLVGNSLSRA GPGNEPLEPLTMEEMFFRSTELLTDLGIEEFMRGSMQTTAQEVDIMI HDALRNFLFSEVEEEEGFDLIALNLQRGRDHAI PKFNEL RVALNME PLGSFAELTANEEVQAGMEEVYGT I DDVEAWI GMVAEDHMPDSSVGPTMGELWRTEYTRIRDGDMFFYQNSETFPAELA ELPLITRLDEPGSVLRDIIIRNSEITEEEMNESPFETS 


\section{SUPPLEMENTARY REFERENCES}

1 Chekan, J. R. et al. (2019) Scalable biosynthesis of the seaweed neurochemical, kainic acid. Angew. Chem. 58, 8454-8457.

2 Hadziavdic, K. et al. (2014) Characterization of the 18S rRNA gene for designing universal eukaryote specific primers. PLoS One 9, e87624.

3 Zuccarello, G. C., Burger, G., West, J. A. \& King, R. J. (1999) A mitochondrial marker for red algal intraspecific relationships. Mol. Ecol. 8, 1443-1447.

4 Tamura, K. \& Nei, M. (1993) Estimation of the number of nucleotide substitutions in the control region of mitochondrial-DNA in humans and chimpanzees. Mol. Biol. Evol. 10, 512-526.

5 Wever, R., Krenn, B. E. \& Renirie, R. (2018) Marine vanadium-dependent haloperoxidases, their isolation, characterization, and application. Method Enzymol. 605, 141-201.

6 Thapa, H. R. et al.(2016) A squalene synthase-like enzyme initiates production of tetraterpenoid hydrocarbons in Botryococcus braunii Race L. Nat. Commun. 7, 11198.

7 Bolger, A. M., Lohse, M. \& Usadel, B. (2014) Trimmomatic: a flexible trimmer for Illumina sequence data. Bioinformatics 30, 2114-2120.

8 Bushnell, B., Rood, J. \& Singer, E. (2017) BBMerge - Accurate paired shotgun read merging via overlap. PLoS One 12, e0185056.

9 Bankevich, A. et al. (2012) SPAdes: a new genome assembly algorithm and its applications to single-cell sequencing. J. Comput. Biol. 19, 455-477.

10 Collen, J. et al. (2013) Genome structure and metabolic features in the red seaweed Chondrus crispus shed light on evolution of the Archaeplastida. Proc. Natl. Acad. Sci. USA 110, 5247-5252.

11 Hughes, A. J. \& Keatinge-Clay, A. (2011) Enzymatic extender unit generation for in vitro polyketide synthase teactions: structural and functional showcasing of Streptomyces coelicolor MatB. Chem. Biol. 18, 165-176.

12 Maier, T. et al. (2007) PYRAZOLOPYRIMIDONES. PCT/EP2007/055846.

13 Quadri, L. E. N. et al. (1998) Characterization of Sfp, a Bacillus subtilis phosphopantetheinyl transferase for peptidyl carrier protein domains in peptide synthetases. Biochemistry 37, 15851595 .

14 Thapa, H. R., Lail, A. J., Garg, N. \& Agarwal, V. (2018) Chemoenzymatic synthesis of starting materials and characterization of halogenases requiring acyl carrier protein-tethered substrates. Method Enzymol. 604, 333-366.

15 Miller, I. J. et al. (2019) Autometa: automated extraction of microbial genomes from individual shotgun metagenomes. Nucleic Acids Res. 47, e57. 
16 Stanke, M. \& Morgenstern, B. (2005) AUGUSTUS: a web server for gene prediction in eukaryotes that allows user-defined constraints. Nucleic Acids Res. 33 W465-7.

17 Livak, K. J. \& Schmittgen, T. D. (2001) Analysis of relative gene expression data using real-time quantitative PCR and the $2^{-\Delta \Delta \mathrm{CT}}$ method. Methods 25, 402-408.

18 Gietz, R. D. \& Schiestl, R. H. (1991) Applications of high-efficiency lithium-acetate transformation of Intact yeast-cells using single-stranded nucleic-acids as carrier. Yeast 7, 253-263.

19 Montllor-Albalate, C. et al. (2019) Extra-mitochondrial $\mathrm{Cu} / \mathrm{Zn}$ superoxide dismutase (Sod1) is dispensable for protection against oxidative stress but mediates peroxide signaling in Saccharomyces cerevisiae. Redox Biol. 21.

20 Kumar, S., Stecher, G. \& Tamura, K. (2016) MEGA7: Molecular evolutionary genetics analysis version 7.0 for bigger datasets. Mol. Biol. Evol. 33, 1870-1874.

21 Sievers, F. \& Higgins, D. G. (2018) Clustal Omega for making accurate alignments of many protein sequences. Protein Sci. 27, 135-145.

22 Agarwal, V. et al. (2015) Chemoenzymatic synthesis of acyl Coenzyme A substrates enables in situ labeling of small molecules and proteins. Org Lett 17, 4452-4455.

23 Reynolds, S. M., Kall, L., Riffle, M. E., Bilmes, J. A. \& Noble, W. S. (2008) Transmembrane topology and signal peptide prediction using dynamic bayesian networks. Plos Comput. Biol. 4 , e1000213.

24 Panday, A., Sahoo, M. K., Osorio, D. \& Batra, S. (2015) NADPH oxidases: an overview from structure to innate immunity-associated pathologies. Cell Mol. Immunol. 12.

25 Magnani, F. et al. (2017) Crystal structures and atomic model of NADPH oxidase. Proc. Natl. Acad. Sci. USA 114, 6764-6769.

26 Lee, J. et al. (2013) Structural and functional insight into an unexpectedly selective Nmethyltransferase involved in plantazolicin biosynthesis. Proc. Natl. Acad. Sci. USA 110, 1295412959.

27 Agarwal, V. et al. (2014) Biosynthesis of polybrominated aromatic organic compounds by marine bacteria. Nat. Chem. Biol. 10. 